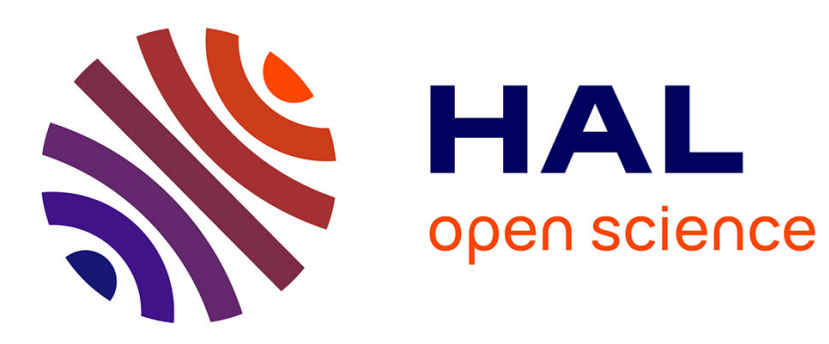

\title{
Flow boiling in tube under normal gravity and microgravity conditions
}

Marine Narcy, Erik de Malmazet, Catherine Colin

\section{To cite this version:}

Marine Narcy, Erik de Malmazet, Catherine Colin. Flow boiling in tube under normal gravity and microgravity conditions. International Journal of Multiphase Flow, 2014, vol. 60, pp. 50-63. 10.1016/j.ijmultiphaseflow.2013.11.011 . hal-01120714

\section{HAL Id: hal-01120714 https://hal.science/hal-01120714}

Submitted on 26 Feb 2015

HAL is a multi-disciplinary open access archive for the deposit and dissemination of scientific research documents, whether they are published or not. The documents may come from teaching and research institutions in France or abroad, or from public or private research centers.
L'archive ouverte pluridisciplinaire HAL, est destinée au dépôt et à la diffusion de documents scientifiques de niveau recherche, publiés ou non, émanant des établissements d'enseignement et de recherche français ou étrangers, des laboratoires publics ou privés. 


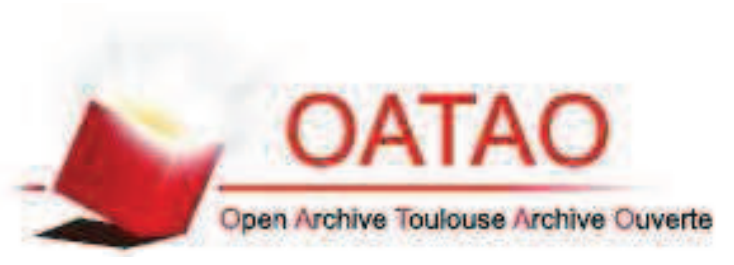

\section{Open Archive Toulouse Archive Ouverte (OATAO)}

OATAO is an open access repository that collects the work of Toulouse researchers and makes it freely available over the web where possible.

This is an author-deposited version published in: http://oatao.univ-toulouse.fr/ Eprints ID: 11190

To link to this article : DOI:10.1016/j.ijmultiphaseflow.2013.11.011

URL: http://dx.doi.org/10.1016/j.ijmultiphaseflow.2013.11.011

\section{To cite this version:}

Narcy, Marine and De Malmazet, Eric and Colin, Catherine Flow boiling in tube under normal gravity and microgravity conditions. (2014) International Journal of Multiphase Flow, vol. 60. pp. 50-63. ISSN 0301-9322

Any correspondence concerning this service should be sent to the repository administrator: staff-oatao@ listes.diff.inp-toulouse.fr 


\title{
Flow boiling in tube under normal gravity and microgravity conditions
}

\author{
Marine Narcy, Erik de Malmazet, Catherine Colin* \\ IMFT, University of Toulouse, CNRS, Allée Camille Soula, 31400 Toulouse, France
}

\begin{abstract}
A B S T R A C T
Forced convective boiling experiments of HFE-7000 were conducted in earth gravity and under microgravity conditions. The experiment mainly consists in the study of a two-phase flow through a $6 \mathrm{~mm}$ diameter sapphire tube uniformly heated by an ITO coating. The parameters of the hydraulic system are set by the conditioning system and measurements of pressure drops, void fraction and wall temperatures are provided. High-speed movies of the flow were also taken. The data were collected in normal gravity and during a series of parabolic trajectories flown onboard an airplane. Flow visualisations, temperature and pressure measurements are analysed to obtain flow pattern, heat transfer and wall friction data.
\end{abstract}

Keywords:

Two-phase flow

Microgravity

Heat transfer

Wall friction

\section{Introduction}

Two-phase thermal systems are broadly used in various industrial applications and engineering fields. Flow boiling heat transfer is common in power plants (energy production or conversion), transport of cryogenic liquids and other chemical or petrochemical processes. Thus, the understanding of boiling mechanisms is of importance for accidental off-design situations. These systems take advantage of latent heat transportation, which generally enables a good efficiency in heat exchanges. For that reason, two-phase thermal management systems are considered as extremely beneficial for space applications. Indeed, in satellites or space-platforms, the major thermal problem is currently to remove the heat generated by devices from the inside into space, in order to ensure suitable environmental and working conditions. Moreover, the growing interest for space applications such as communication satellites and the increasing power requirements of on-board devices require sophisticated management systems capable to deal with larger heat loads. Since the heat transfer capacity associated with phase change is typically large and with a relatively little increase in temperature, this solution could mean decreased size and weight of thermal systems. But boiling is a complex phenomenon which combines heat and mass transfers, hydrodynamics and interfacial phenomena. Furthermore, gravity affects the fluid dynamics and may lead to unpredictable performances of thermal management systems. It is thus necessary to perform experiments directly in (near) weightless environments. Besides the ISS,

\footnotetext{
* Corresponding author.

E-mail address: colin@imft.fr (C. Colin).
}

microgravity conditions can be simulated by means of a droptower, parabolic flights on board an aircraft or a sounding-rocket.

Although flow boiling is of great interest for space applications under microgravity conditions, few experiments have been conducted in low gravity. These experiments provided a partial understanding of boiling phenomena and have been mostly performed for engineering purposes such as the evaluation of ISS ("International Space Station") hardware or two-phase loop stability. Moreover, flow boiling heat transfer experiments in microgravity (referred to as $\mu-g$ ) require large heat loads and available space. They are subject to severe restrictions in the test apparatus, do not last long and offer few opportunities to repeat measurements, which could explain the lack of data and of coherence between existing measurements. Nevertheless, several two-phase flow (gas-liquid flow and boiling flow) experiments have been conducted in the past forty years and enabled to gather data about flow patterns, pressure drops, heat transfers including critical heat flux and void fraction in thermohydraulic systems. Previous state of the art and data can be found in the papers of Colin et al. (1996), Ohta (2003), and Celata and Zummo (2009). Several studies have been carried out under microgravity conditions in order to classify adiabatic two-phase flows by various patterns through observation and visualisations of the flow. Various flow patterns have been identified at different superficial velocities of liquid $j_{l}$ and gas $j_{g}$, for both adiabatic gas-liquid flows and boiling flows: bubbly flow, slug flow and annular flow. Transitions between these flow patterns have been studied too: transition between bubbly and slug flow, and transition between slug and annular flow or frothy slug-annular flow. The determination of these transitions is of importance because the wall friction and wall heat transfer are very sensitive to the flow pattern. Colin et al. (1991) and Dukler 
et al. (1988) drew a map based on void fraction transition criteria to predict patterns in liquid-gas flows. These patterns were also observed in flow boiling for heat transfer below the critical heat flux by Ohta (2003), Reinarts (1993) and more recently by Celata and Zummo (2009). The transition between bubbly and slug flows occurs from coalescence mechanisms. Coalescence can be promoted or inhibited depending on the value of the Ohnesorge number. A general flow pattern map for bubbly and slug flows based on the value of the Oh number was proposed by Colin et al. (1996) for air-water flow and also for boiling refrigerants. The Ohnesorge number $O h=\left(\rho v^{2} / \sigma D\right)^{1 / 2}$ is based on the pipe diameter $D$ and on the fluid properties: $v, \rho, \sigma$, the kinematic viscosity, density and surface tension of the liquid, respectively. A criterion based on the Ohnesorge number was also established by Jayawardena et al. (1997). The transition between slug and annular flows has also been investigated by several authors, who proposed criteria based on transition void fraction value as Dukler et al. (1988), critical value of a vapour Weber number as Zhao and Rezkallah (1993), balance between gas inertia and surface tension according to Reinarts (1993) and Zhao and Hu (2000).

The estimation of cross-sectional averaged void fraction $\alpha$ or mean gas velocity $U_{g}$ is a key-point for the calculation of wall and interfacial frictions. It has been shown that the mean gas velocity $U_{g}=j_{g} / \alpha$ is well predicted by a drift flux model $U_{g}=C_{0} \cdot j$ for bubbly and slug flow (Dukler et al., 1988), $j=j_{l}+j_{g}$ being the mixture velocity and $C_{0}$ a coefficient depending on the local void fraction and gas velocity distributions. Very few experimental data on film thickness in microgravity is available, and only for gas-liquid annular flows (Bousman et al., 1996; de Jong and Gabriel, 2003). Different experimental technics have been used to determine the cross-sectional averaged void fraction: capacitance probes (Elkow and Rezkallah, 1997), conductance probes (Colin et al., 1991) and optical techniques.

Regarding the measurements of the wall shear stress, most of the studies performed under microgravity conditions concern gas-liquid flow without phase change (Zhao and Rezkallah, 1995; Colin and Fabre, 1995; Colin et al., 1996). Some results also exist for liquid-vapour flow (Chen et al., 1991), but in an adiabatic test section. The frictional pressure drop has been compared (Zhao and Rezkallah, 1995; Chen et al., 1991) to different empirical models (homogeneous model, Lockhart and Martinelli's model Lockhart and Martinelli, 1949). Recently, Awad and Muzychka (2010) and Fang et al. (2012) proposed a modified expression of the correlation of Lockhart and Martinelli and found good agreement with the experimental data. Very few studies reported data on the interfacial shear stress in annular flow (Dukler et al., 1988). This can be explained by the difficulty of measuring simultaneously pressure drops and film thickness.

Little research on flow boiling heat transfer in microgravity has been conducted, mainly because of the restrictive experimental conditions. Lui et al. (1994) carried out heat transfer experiments in subcooled flow boiling with R113 through a tubular test Section (12 mm internal diameter, $914.4 \mathrm{~mm}$ length). Heat transfer coefficients were approximately 5-20\% higher in microgravity, generally increasing with higher qualities, which was believed to be caused by the greater movement of vapour bubbles on the heater surface. Ohta $(1997,2003)$ studied flow boiling of R113 in a $8 \mathrm{~mm}$ internal diameter vertical transparent tube, internally coated with a gold film, both on ground and during parabolic flight campaigns, and for the preparation of a future experiment on board the International Space Station. The authors examined various flow patterns and the influence of gravity levels on heat transfer coefficients for flow boiling. They found that, in bubbly flow, heat transfer is similar in normal and microgravity conditions, despite different bubble sizes at low mass fluxes. In annular flow, heat transfer coefficients are smaller in microgravity at low heat flux. The difference in the heat transfer coefficient in annular flow between normal and microgravity conditions disappears at high flux in the nucleate boiling regime. Celata and Zummo (2009) performed subcooled flow boiling experiments with FC-72 in Pyrex tubes (2, 4 and $6 \mathrm{~mm}$ internal diameters). They found that in bubbly and slug flow the influence of gravity is not evident for liquid velocities larger than $0.25 \mathrm{~m} / \mathrm{s}$ or qualities larger than 0.3 . Recently, a new technique for the measurement of heat transfer distributions has also been developed by Kim et al. (2012). They used an IR camera to determine the temperature distribution within a multilayer consisting of a silicon substrate coated with a thin insulator. They have not quantified the difference between microgravity and normal gravity yet. No clear conclusion on the influence of the buoyancy force on the heat transfer can be pointed out from these experiments. It seems to be strongly dependent on the mass flux and quality values. Work is still needed to confirm and give coherence to the previous results of the literature on flow boiling and to compare the data sets obtained by the different authors.

The objective of the present work is to collect, analyse and compare flow boiling data in normal gravity and under microgravity conditions. A refrigerant circulates in a heated tube of $6 \mathrm{~mm}$ inner diameter coated by a conductive film heated by the Joule effect. Its outer diameter is $8 \mathrm{~mm}$. Flow patterns, void fraction, film thickness, wall and interfacial shear stresses, and heat transfer are investigated. This paper presents the main results of the measurement campaigns. The first section describes the experimental apparatus and the measurement techniques. The data reduction to obtain the mass quality, gas velocity, wall shear stress and heat transfer coefficient is described in a second section. Finally the experimental results obtained in $\mu-g$ and $1-g$ experiments are presented and discussed.

\section{Experimental set-up and measurement techniques}

\subsection{Hydraulic loop}

The experimental set-up used to study vapour-liquid flows in $1-g$ and $\mu-g$ mainly consists of a hydraulic loop represented in Fig. 1. In this pressurised circuit, the working fluid is the refrigerant 1-methoxyheptafluoropropane $\left(\mathrm{C}_{3} \mathrm{~F}_{7} \mathrm{OCH}_{3}\right)$, commonly referred to as HFE-7000. This fluid has been chosen for safety reasons due to restrictions in $\mu-g$ experiments and because of its low saturation temperature at atmospheric pressure $\left(34^{\circ} \mathrm{C}\right.$ at $\left.1 \mathrm{bar}\right)$, and its low latent heat of vapourization $(142 \mathrm{~kJ} / \mathrm{kg}$ against $2257 \mathrm{~kJ} / \mathrm{kg}$ for water). In the circuit, the HFE-7000 may be in a liquid or a liquid-vapour state depending on the portion of the hydraulic loop, but it is never in a pure vapour state. The HFE-7000 is first pumped at liquid state by a gear pump while the liquid flow rate is measured by a Coriolis flowmeter. Then the fluid circulates through two serial preheaters. Its temperature can be adjusted below the saturation temperature (subcooled conditions) or the fluid can be preheated to its boiling point and partially vapourised (saturated conditions). It then enters a $22 \mathrm{~cm}$ long vertical stainless steel tube just upstream the test section, which enables the flow to fully develop. In the test section, the HFE-7000 (upward flow) is further vapourised in a sapphire tube heated by Joule effect through an outside ITO coating. The fluid exiting the test section is then condensed and cooled $10^{\circ} \mathrm{C}$ below its saturation temperature by four cold plates containing Peltier modules and fans before it enters the pump again. The pressure is adjusted in the circuit via a volume compensator, whose bellows can be pressurised by air.

The loop pressure is set from 1 to 2 bars and the fluid circulates with mass fluxes $G$ between 100 and $1200 \mathrm{~kg} / \mathrm{m}^{2} / \mathrm{s}$. A wide range of flow boiling regimes is studied, from subcooled flow boiling to 


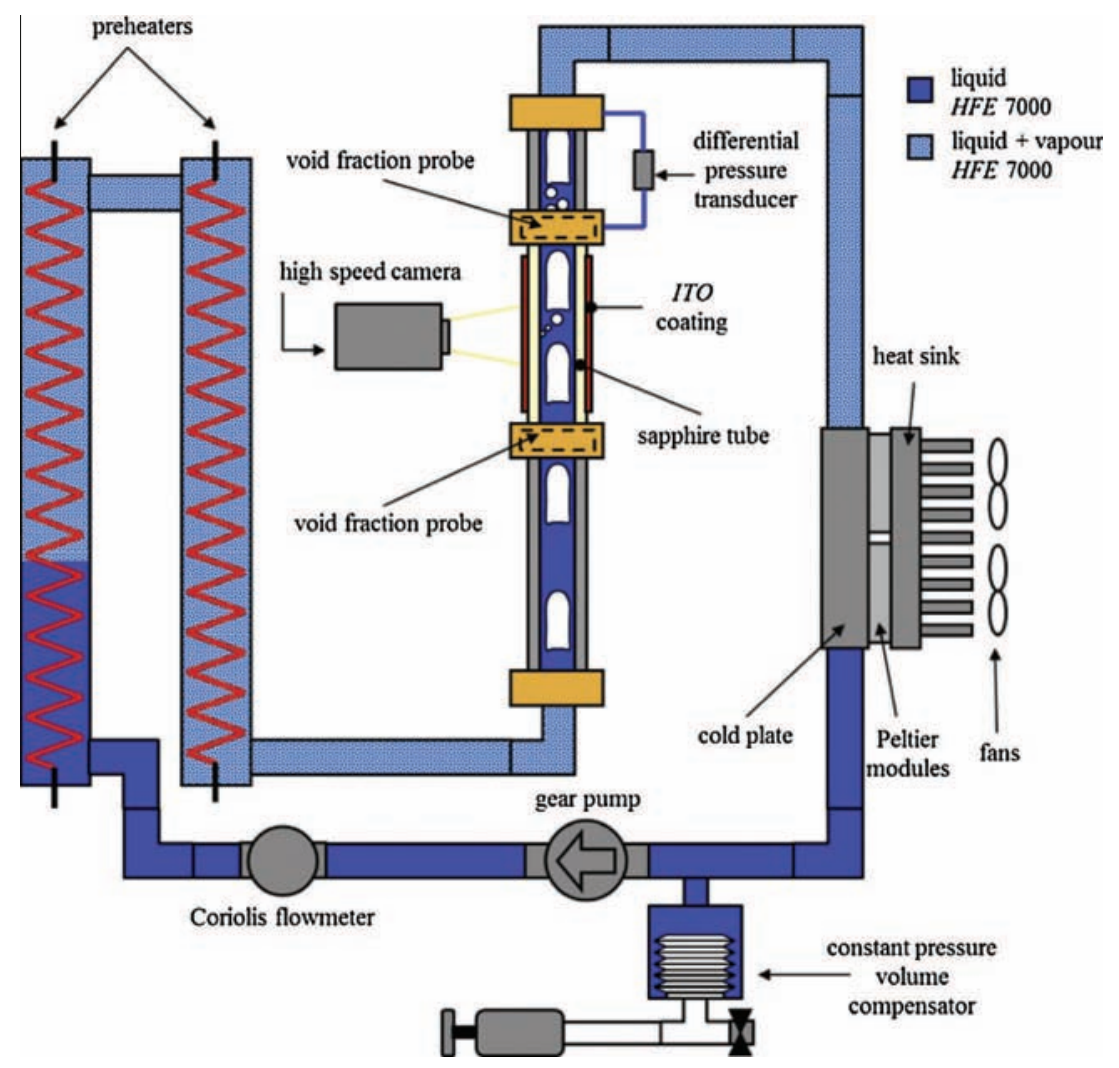

Fig. 1. Experimental set-up.

saturated flow boiling, by adjusting the power input of the heaters (vapour mass qualities $x$ up to 0.8 ) and the power through the ITO coating (wall heat flux $q_{\text {ow }}$ up to $4.5 \mathrm{~W} / \mathrm{cm}^{2}$ ). The total vapour quality at the outlet of the test section can be set up to 0.9 .

The test section mainly consists of a $20 \mathrm{~cm}$ long sapphire tube with a $6 \mathrm{~mm}$ inner diameter $D$ and a $1 \mathrm{~mm}$ thickness. The outer surface is coated on a length of $16.4 \mathrm{~cm}$ with ITO, an electrical conductive and transparent coating that enables a uniformly heating by Joule effect and a visual display of the flow.

\subsection{Measurement technique}

Various measurement instruments provide experimental data for the calculation of the wall shear stress, heat transfer coefficient, gas velocity or film thickness.

\subsubsection{Pressure drop}

Two P305D Valydine differential pressure transducers (to crosscheck) measure the pressure drops along an adiabatic section of $20 \mathrm{~cm}$ long at the outlet of the test section (see Fig. 1), with a precision of 0.5 mbar; they are calibrated at IMFT using two manometers with different ranges.

\subsubsection{Absolute pressure}

Two Omega pressure transmitters $24 \mathrm{~V}$ DC are used to calculate the saturation temperature at the inlet and outlet of the sapphire tube. No differential pressure measurement is performed on this section.

\subsubsection{Temperature}

Type $\mathrm{K}$ thermocouples measure the flow temperature at the test section inlet and outlet, with a precision of $\pm 0.2^{\circ} \mathrm{C}$. Two type $\mathrm{T}$ thermocouples are also used to measure the temperature difference between a hot junction and a cold junction located at the inlet and outlet of the test section, respectively. This differential thermocouple allows a very accurate measurement of the fluid temperature difference between both ends of the sapphire tube. Pt100 probes measure the ambient temperature and the external surface temperature of the sapphire tube at four different positions (at a distance of $45,73,106,133 \mathrm{~mm}$ from the beginning of the heated length), with a precision of $\pm 0.1^{\circ} \mathrm{C}$. We used Pt100 probes that are specifically designed for wall temperature measurements. They are flat and mechanically squeezed against the ITO coating by an O-ring in order to reduce thermal resistance. The measurement technique for the heat flux is validated in single-phase flow by comparison of the measurements with classical correlations in the next section. Both thermocouples and Pt100 probes are calibrated using a silicone oil bath and a reference Pt100 probe $\left( \pm 0.01{ }^{\circ} \mathrm{C}\right.$ with calibration certificate).

\subsubsection{Flow visualisations}

A high-speed camera PCO 1200 HS with the associated backlight provides movies of the flow through the transparent ITO coating on the sapphire tube. The camera field of view is $1000 * 350$ pixels $^{2}$ and the acquisition frequency is 1000 or 1500 images per second depending on the flow regime. The spatial resolution of the images is 33.3 pixels $/ \mathrm{mm}$. Only a short length of $30 \mathrm{~mm}$ is imaged by the camera. It is located between the 2nd and 3rd Pt100 probes.

\subsubsection{Void fraction}

Specific void fraction probes were designed and built at IMFT to provide accurate data of the volume fraction of the vapour phase at the inlet and outlet of the test section. These sensors are made of two copper electrodes (and four guard electrodes) of around 1 
$\mathrm{cm}^{2}$ placed on both sides of the two-phase flow as can be seen in Fig. 2a.

The capacitance measured between the electrodes depends on the permittivity of the considered volume and can be related to the void fraction after calibration. Liquid HFE-7000 and Teflon rods whose permittivity is close to the one of HFE-7000 vapour are used to mimic the annular flow configuration for the calibration. For each void fraction value, the reduced capacitance $C^{*}=\left(C-C_{v}\right) /\left(C_{l}-C_{v}\right)$ is measured and plotted on a calibration curve (Fig. 2b). C, $C_{v}$ and $C_{l}$ are the measured capacitance for the liquid-vapour mixture, for the vapour alone and for the liquid alone, respectively. The geometry of the sensor has been designed to minimise the sensitivity of the measurement to the void fraction distribution and thus to the flow pattern. Nevertheless a direct calibration measuring the bubble velocities from image processing is recommended for bubbly flows. A numerical model of capacitances in series and parallel has also been developed to combine both flow regimes in a single calibration curve (Fig. 2b). The signal sensibility (corresponding to the capacitance difference between liquid state and vapour state $C_{l}-C_{v}$ ) is around $0.3 \mathrm{pF}$. The accuracy on the measurement is $0.001 \mathrm{pF}$, which gives an uncertainty less than $1 \%$ on the capacitance data. The uncertainty on the void fraction itself depends on the precision of the calibration and is estimated at $2 \%$.

The acquisition system consists of a 36 channels National Instrument deck, two laptops with LabVIEW interfaces and a computer for the acquisition of camera images using Cameware software.

\subsection{Measurement campaigns}

Experiments were conducted both on ground and under microgravity conditions. A near-weightless situation is simulated during a parabolic flight campaign which consists of three flights with 31 parabolas per flight. Each parabola provides up to $22 \mathrm{~s}$ of microgravity with a gravity level smaller than $\pm 0.03 \mathrm{~g}$, with $g=9.81 \mathrm{~m} / \mathrm{s}^{2}$. Parabolic flight campaigns are the only sub-orbital opportunity for experimenters to work directly on their experimental apparatus under microgravity conditions without too severe restrictions on the size of their set-up and the available power on board. Two parabolic flight campaigns (May 2011 and April 2012) provided data for the results presented in this article. The liquid mass flux is imposed by a gear pump. During one parabola, the gravity level drastically changes between $1-g, 1.8-g$ and $\mu-g$, leading to pressure variations in the test section. Since no PID regulation of the rotating speed of the pump was used, a variation of the mass flux was observed between the different phases of a parabola. The mass flux is steady during $1-g$ phases between two parabolas ( $G=100,200$ or $400 \mathrm{~kg} / \mathrm{s}$ ) $\mathrm{m}^{2}$ ), but it drops a little bit during the $1.8-\mathrm{g}$ period and then increases in microgravity (as can be seen in Fig. 3). This is the reason why experimental points do not exactly fit the $G$ isocurves on the flow pattern map in microgravity. Nevertheless, after a short transient period, the flow rate stabilises in microgravity and a steady state is reached.

During the on-ground measurement campaign, relevant parabolas were reproduced in order to compare data obtained in normal gravity and under microgravity conditions. A series of parametric runs has also been conducted to complete the dataset.

\section{Data reduction}

In the next sections, the experimental results on wall and interfacial shear stresses, quality, vapour velocity, film thickness and heat transfer coefficients will be presented. These values are deduced from the measurements of wall and liquid temperatures, heat flux, pressure drop and void fraction by using mass, momentum and enthalpy balance equations, which are detailed in this section. The measurement techniques are validated in single-phase flow by comparison of the experimental results with classical correlations of the literature.

\subsection{Wall friction}

The momentum balance equation for the liquid-vapour mixture in steady state enables to write the wall friction along a heated test section according to the pressure drop, the void fraction, the mass flux and the vapour quality:

$\frac{d P}{d z}=\frac{4}{D} \tau_{w}-\frac{d}{d z}\left[\frac{G^{2} x^{2}}{\rho_{v} \alpha}+\frac{G^{2}(1-x)^{2}}{\rho_{l}(1-\alpha)}\right]-g\left[\rho_{v} \alpha+\rho_{l}(1-\alpha)\right]$

where $P, G, x, \alpha, g, \rho_{l}, \rho_{v}$ are the pressure, mass flux, quality, void fraction, acceleration of gravity, density of liquid and vapour, respectively. $\tau_{w}$ is the wall friction, which is negative. The second term of the Right Hand Side (RHS) is an acceleration term, that has to be taken into account when quality and void fraction evolve along the test section. Since the pressure drop measurements were performed along an adiabatic test section in our experiment, this term is equal to zero. The last term of the RHS is the hydrostatic

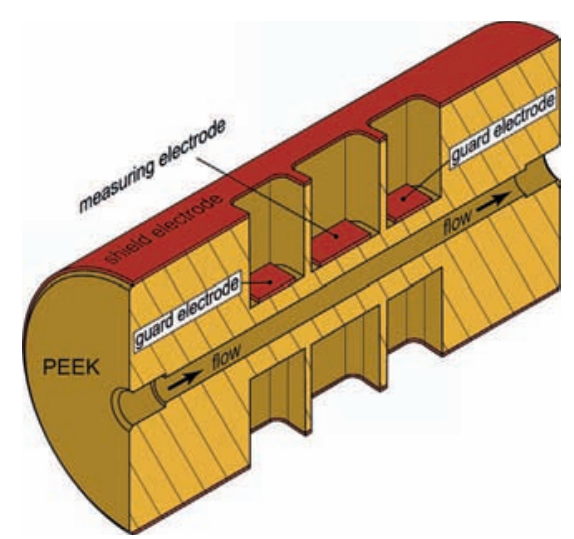

(a) Schematic of the void fraction probe.

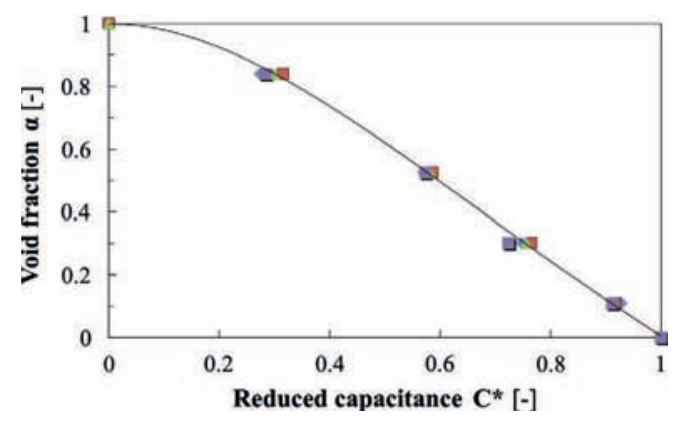

(b) Calibration curve.

Fig. 2. Void fraction probe. 


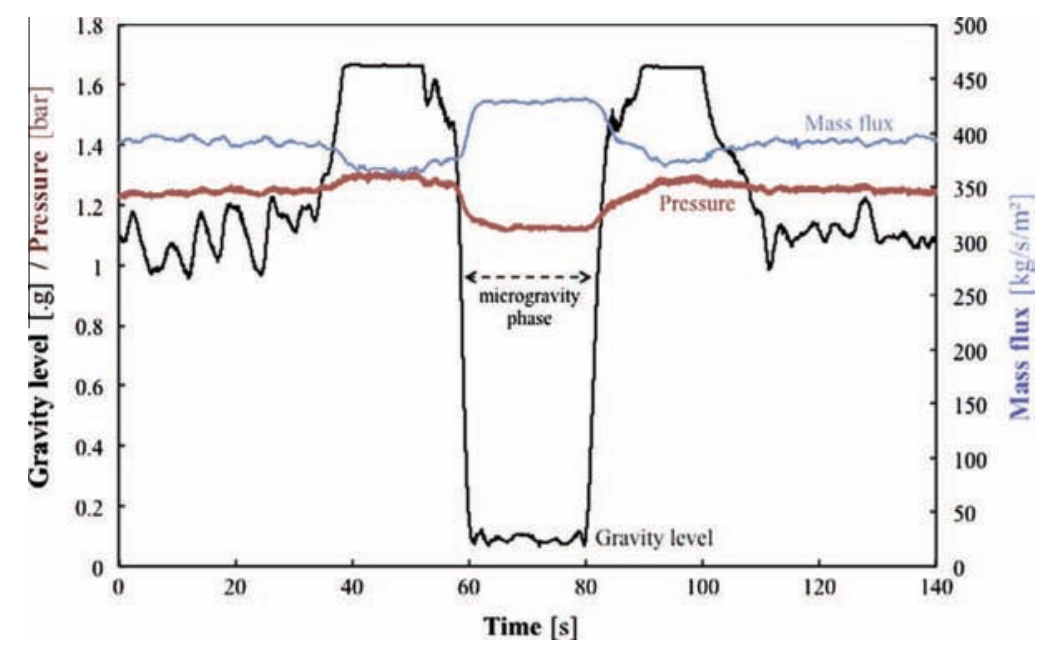

Fig. 3. Pressure and mass flux evolutions during one parabola.

pressure gradient that is negligible in microgravity. On ground, in upward flow, this last term is dominant, thus the accuracy of the wall shear stress measurement is directly linked to the accuracy of the void fraction measurement itself. An averaged value of the wall shear stress is deduced from the pressure drop and void fraction measurements by integration of Eq. (1). Measurements for single-phase liquid flows have enabled to validate the measurement technique by comparing the data to Blasius's correlation:

$f_{w}=\frac{\tau_{w}}{1 / 2 \rho_{j} j_{l}^{2}}=0.079 R e^{-0.25}$

where Re is the Reynolds number of the liquid flow. Fig. 4 shows the measurements obtained with the two differential transducers for single-phase liquid flows at various mass fluxes and Blasius's correlation. The dashed lines correspond to Blasius's correlation at $\pm 10 \%$. The agreement is good considering that the measurement range of the transducers is adapted to two-phase flow with much larger pressure drops.

\subsection{Wall heat transfer}

The heat transfer coefficient is measured at the inner wall of the sapphire tube. A cross-section of the sapphire tube is represented in Fig. 5. $T_{i w}$ and $T_{o w}$ are the inner and outer temperatures of the sapphire tube wall, respectively. $T_{e \infty}$ is the temperature of the ambient air far from the tube (measured by a Pt100 probe) and

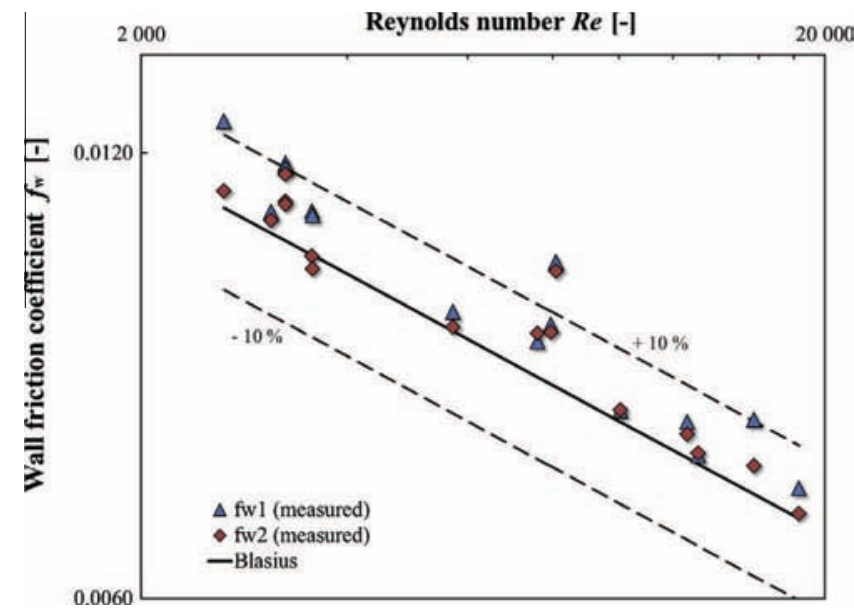

Fig. 4. Wall friction coefficient and Blasius correlation in single-phase flow.

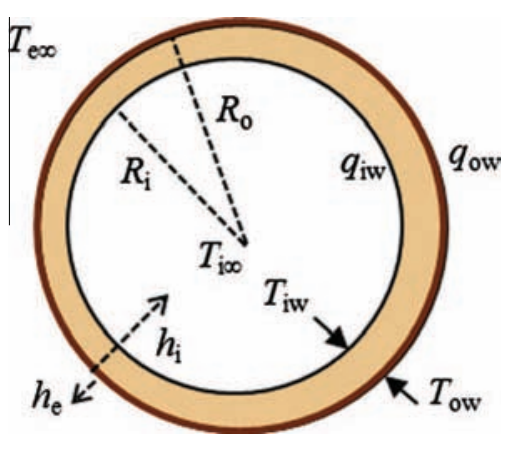

Fig. 5. Scheme of the heated test section.

$T_{i \infty}$, is the liquid bulk temperature in the tube. $T_{\text {in }}$ and $T_{\text {out }}$ are the liquid bulk temperatures at the inlet and outlet of the sapphire tube. The inner and outer radii of the sapphire tube are denoted by $R_{i}$ and $R_{0}$, respectively. The sapphire thermal conductivity is denoted by $k$ and is equal to $22 \mathrm{~W} / \mathrm{m} / \mathrm{K}$. The ITO coating on the external surface of the test section provides a heat flux $q_{\text {ow }}$. The heat flux $q_{i w}$ delivered to the fluid is considered as equal to $q_{\text {ow }}$ corrected by the radii ratio $R_{o} / R_{i}$. The heat transfer between the flow and the internal wall of the sapphire tube is characterised by the heat transfer coefficient $h_{i}$. The heat transfer between the environment and the external wall of the sapphire tube (thermal losses) is characterised by the heat transfer coefficient $h_{e}$.

In order to estimate the heat transfer coefficient at the inner wall $h_{i}$ the following hypotheses are made: (1) temperature profiles are axisymmetric. (2) axial conduction is neglected. (3) heat transfer by radiation is neglected.

By using a conduction equation, the temperature at the inner wall $T_{i w}$ can be deduced from the measurements of the temperature at the outer wall $T_{o w}$ and the heat flux $q_{o w}$ applied by Joule effect through the ITO coating:

$T_{o w}-T_{i w}=\left[q_{o w}-h_{e}\left(T_{o w}-T_{e w}\right)\right] \cdot \ln \left(\frac{R_{o}}{R_{i}}\right) \cdot \frac{R_{o}}{k}$

The temperature $T_{o w}$ is measured by the previously described Pt100 probes. The heat transfer coefficient at the inner wall $h_{i}$ and the Nusselt number $\mathrm{Nu}=2 h_{i} R_{i} / k_{l}$ ( $k_{l}$ being the thermal conductivity of the liquid) is deduced from an energy balance through the tube:

$h_{i} \cdot\left(T_{i w}-T_{i \infty}\right)=\frac{R_{o}}{R_{i}}\left[q_{o w}-h_{e}\left(T_{o w}-T_{e \infty}\right)\right]$ 
The temperature evolution between $T_{\text {in }}$ and $T_{\text {out }}$ can be considered as linear or parabolic, which enables to calculate $T_{i \infty}$ all along the sapphire tube. A series of experiments has been conducted in order to evaluate the thermal losses given by the coefficient $h_{e}$. In particular, it can be locally estimated in normal gravity with the local measurement of $T_{o w}$ and the measurement of $T_{e \infty}$ for single or two-phase flow without heating by using a known correlation to estimate $h_{i}$. In this configuration, thermal losses have been estimated for single and two-phase flows with different correlations. The maximal heat transfer coefficient $h_{e}$ that was obtained in normal gravity represents $6 \%$ of heat transfer coefficient $h_{i}$. Experiments with single-phase flows characterised by very low mass fluxes $G$ and high temperatures have allowed us to conclude through a global energy balance about the nature of thermal losses that are considered as negligible. In order to validate the heat transfer measurements, experiments are performed in single-phase flow and the results are compared to the classical correlations in the literature. It is important to notice that the heated length is short and the heat transfer regime is not fully established. Then the entrance effect correction has to be taken into account in order to compare measurements and correlations. For a fully developed turbulent single-phase flow, the Nusselt number $N u_{\infty}$ can be calculated with Gnielinski's correlation (5) (Gnielinski, 1976) valid for fully developed turbulent flow in a wide range of Reynolds numbers $2500<\operatorname{Re}<5.10^{6}$ and Prandtl numbers $0.5<\operatorname{Pr}<2000$ :

$N u_{\infty}=\frac{\left(f_{w} / 2\right) \cdot(R e-1000) \cdot \operatorname{Pr}}{1+12.7\left(f_{w} / 2\right)^{1 / 2} \cdot\left(\operatorname{Pr}^{2 / 3}-1\right)}$

where $f_{w}$ is the wall friction coefficient. In Fig. 6a the measured values of the Nusselt number $N u_{m}=h_{i} \cdot D / k$ are plotted versus the Reynolds number. Since the flow is not thermally developed, these values of the Nusselt number are larger than the values measured in thermally developed flow $N u_{\infty}$. The deviation from the correlation is in inverse proportion to the distance between the temperature sensors and the inlet of the heated section. In order to compare the measurements with the preceding correlations, the measured values of the Nusselt number have been corrected by the entrance effect using Al-Arabi's correlation (Al-Arabi, 1982):

$\frac{N u_{m}}{N u_{\infty}}=1+\frac{\frac{(z / D)^{0.1}}{P r^{1 / 6}}\left(0.68+\frac{3000}{R e^{0.81}}\right)}{z / D}$

Fig. 6b shows the measurements corrected with Al-Arabi's correlation according to the sensor position $z$ and the comparison to Gnielinski's correlation. The experimental data meet the correlations with a maximal error of $\pm 17 \%$. The precision between

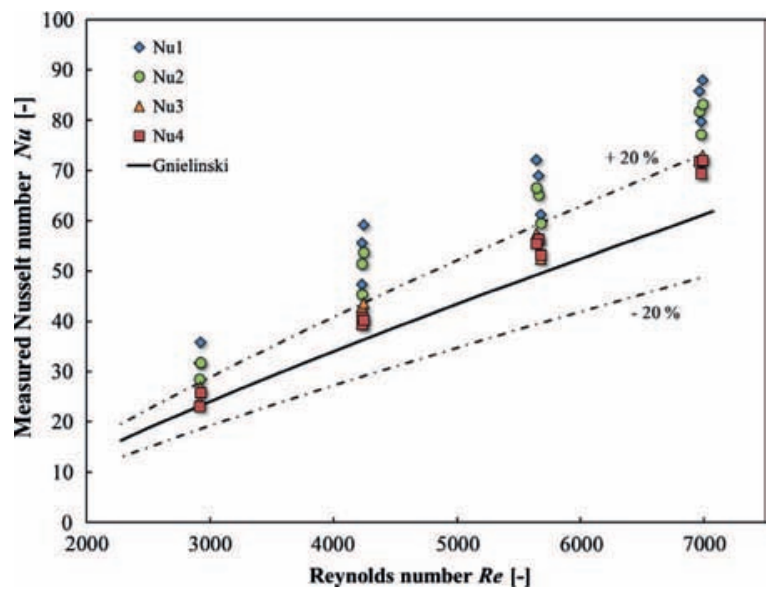

(a) Without any correction. measurements and correlations is satisfying for the whole set of experiments in single-phase flow. It also confirms the weak impact of external thermal heat losses on the measurements.

\subsection{Vapour quality}

The vapour quality can be calculated by using the enthalpy balance equation in steady state. $q_{i w}$ is the inner wall heat flux delivered to the fluid and it will be noted $q$ in the following. $D$ is the inner diameter of the sapphire tube, $z$ is the distance from the inlet of the heated test section, $x$ is the quality at $z, x_{0}$ is the quality at $z=0$. The enthalpy balance equation can be written versus the enthalpies of the liquid phase $h_{l}$ and the vapour phase at saturation temperature $h_{v, \text { sat }}$ :

$$
\begin{aligned}
\frac{4 q z}{D}= & G\left(\left[x h_{v, \text { sat }}(z)+(1-x) h_{l}(z)\right]\right. \\
& \left.-\left[x_{0} h_{v, \text { sat }}(0)+\left(1-x_{0}\right) h_{l}(0)\right]\right)
\end{aligned}
$$

The pressure drop along the test section is low then it does not induce a significant change of the saturation temperature and fluid properties, which will be considered as constant between 0 and $z$. For saturated boiling regimes, the liquid temperature $T_{l}$ is equal to the saturation temperature $T_{\text {sat }}$. The local mass quality $x$ at a distance $z$ from the inlet of the heated section is equal to:

$x=x_{0}+\frac{4 z \cdot q}{G \cdot D \cdot h_{l v}}$

where $h_{l v}$ is the latent heat of vapourisation, $x_{0}$ is the quality at the inlet of the test section, equal to the quality at the outlet of the preheater and calculated from an enthalpy balance in the preheaters. For subcooled boiling regimes, $x_{0}=0, T_{l}$ is smaller than $T_{\text {sat }}$ and the vapour temperature is assumed to be equal to the saturation temperature. The quality $x(z)$ can be deduced from Eq. (7):

$x(z)=\frac{\frac{4 q z}{G D}-\left[h_{l}(z)-h_{l}(0)\right]}{h_{l v}+h_{l, s a t}(z)-h_{l}(z)}=\frac{\frac{4 q z}{G D}-C_{p l}\left(T_{l}(z)-T_{l}(0)\right)}{h_{l v}+C_{p l}\left(T_{s a t}-T_{l}(z)\right)}$

where $C_{p l}$ is the specific heat of the liquid at constant pressure. The wall heat flux leads to an increase of the total enthalpy of the mixture, both by phase change and by increasing the liquid temperature. The fluid temperature is measured at the inlet and outlet of the test section and the temperature evolution between these two points is considered as linear or parabolic. Note that in Eq. (9), quality $x$ is not the thermodynamical quality. The calculation of vapour quality in subcooled boiling is tricky because of the order of magnitude of $x$ and of measurement uncertainties. We can define

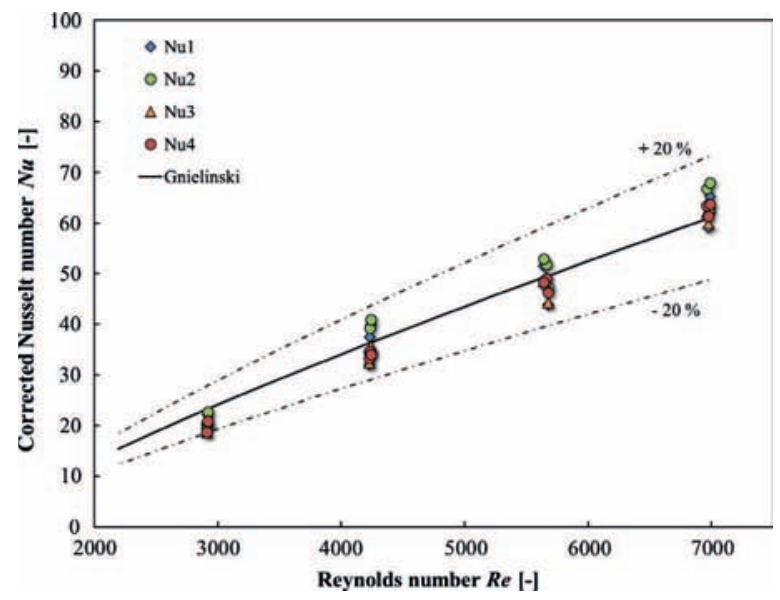

(b) With Al'Arabi's correction.

Fig. 6. Nusselt number versus Reynolds number in single-phase flow. 
measurement errors $\Delta q=1000 \mathrm{~W} / \mathrm{m}^{2}$ on the measured wall heat flux and $\Delta T_{l}=0.2 \mathrm{~K}$ on the measured liquid temperature. Measurement errors on mass flux $G$, and geometrical and physical properties are neglected. The error on the vapour quality is $2 \cdot 10^{-3}$, which is the order of magnitude of $x$ itself for subcooled regimes at low vapour qualities. This error was confirmed by an analysis of flow videos that compared the mean bubble velocity measured from image processing and those calculated using the void fraction and the quality values.

\section{Results and discussion}

Experimental results concerning flow regimes, void fraction, film thickness, wall and interfacial shear stresses and finally heat transfer coefficient are presented in this section and compared to classical models of the literature.

\subsection{Flow pattern}

The high speed camera enables us to visualise flow patterns for various mass fluxes $G$, vapour qualities $x$ at the inlet of the test section and heat fluxes $q$ through the ITO coating. Three main flow patterns have been observed under both normal gravity and microgravity conditions: bubbly flow, slug flow and annular flow. The relevant parameter used to study the evolution of flow patterns is the vapour quality. At low vapour qualities corresponding to subcooled regimes $\left(T_{l}<T_{\text {sat }}\right.$ ), bubbly flows occur. Bubbles are nucleated on the heated wall, they slide along the wall and detach. Bubbles grow due to phase change and also by coalescence. Fig. 7 shows a comparison between bubbly flows in $1-g$ and $\mu-g$ for the same parameters $(G, x$ and $q$ ) and a liquid subcooling $\Delta T_{\text {sub }}=T_{\text {sat }}-T_{l}=20^{\circ} \mathrm{C}$. The impact of gravity level on the bubble size and shape is not significant in the videos for a high mass flux of $540 \mathrm{~kg} / \mathrm{m}^{2} / \mathrm{s}$, but it can be clearly seen for a lower mass flux of $200 \mathrm{~kg} / \mathrm{m}^{2} / \mathrm{s}$. At this low mass flux, under microgravity conditions, bubbles are larger than in normal gravity and are not deformed, because they have a very small relative velocity compared to the liquid velocity. The larger bubble size in microgravity can be explained by both the larger bubble diameter at detachment and the higher rate of coalescence due to the small relative motion of the bubbles.
In saturated flow boiling, annular flow regime is mostly observed for quality above 0.1 (Fig. 8). The liquid is flowing at the wall around a vapour core. The liquid film can become very thin and wavy because of the strong interfacial shear stress induced by the vapour core flow. Roll waves at the vapour-liquid interface are visible on the videos. At the highest qualities and mass fluxes, some liquid droplets are also detached from the film surface and entrained into the vapour core.

Several intermediate regimes are observed between bubbly and annular flow regimes which are themselves clearly described: slug flows (Fig. 9), churn flows and other transition flows that are difficult to identify. These regimes occur for low liquid subcoolings or for saturated boiling at low qualities. From bubbly flow, as quality increases, dense bubble distributions including a few Taylor bubbles can be observed. Coalescence phenomenon then leads to slug flow with Taylor bubbles, whose length increases with vapour quality. Once the gas core is no longer interrupted by liquid plugs, annular flow is observed.

The flow pattern can be determined from flow visualisations but also from the signal of the void fraction sensors (Fig. 10). Bubbly flows correspond to low void fractions while annular flows data (with the vapour core) are observed for higher void fraction values. Slug flow is characterised by its intermittency, which is clearly visible on the signal oscillating between low and high void fraction values, even if spatial resolution and time resolution of the capacitance measurement do not allow to clearly see the slug passage.

The evolution of flow patterns according to the liquid and vapour superficial velocities can be plotted on flow patterns maps that illustrate all the runs that were performed on-ground (Fig. 11) and during parabolic flight campaigns (Fig. 12). Regimes are indicated according to the superficial vapour velocity $j_{v}$ and superficial liquid velocity $j_{l}$, and iso-curves for mass flux $G$ and vapour quality xare also plotted on these figures. The same flow patterns are observed in $1-g$ and $\mu-g$ conditions for about the same flow conditions $j_{l}$ and $j_{v}$.

\subsection{Wall and interfacial friction factors}

The wall shear stress $\tau_{w}$ can be deduced from the pressure drop and void fraction measurements using Eq. (1). The second term of the RHS is equal to zero since the pressure drop measurements are

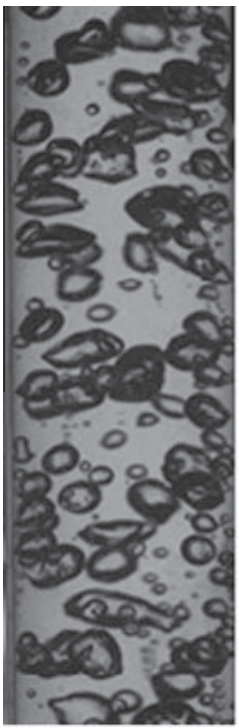

(a)

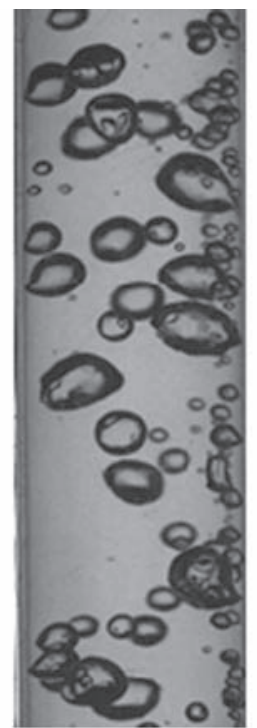

(b)

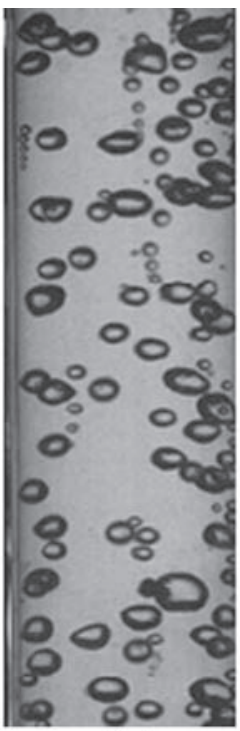

(c)

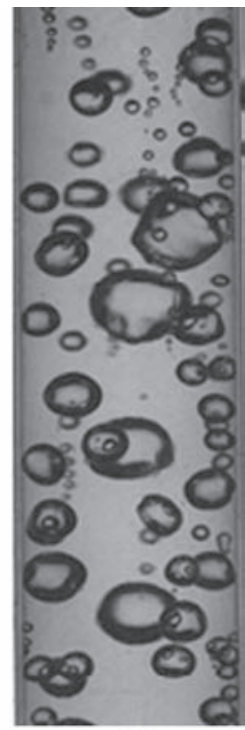

(d)

Fig. 7. Flow visualisations for bubbly flows, $\Delta T_{\text {sub }}=12{ }^{\circ} \mathrm{C}, q=2 \mathrm{~W} / \mathrm{cm}^{2}$, (a) $G=540 \mathrm{~kg} / \mathrm{m}^{2} / \mathrm{s}$ in $1-g$, (b) in $\mu-g$ and (c) $G=220 \mathrm{~kg} / \mathrm{m}^{2} / \mathrm{s}$ in $1-g$, (d) in $\mu-g$. 

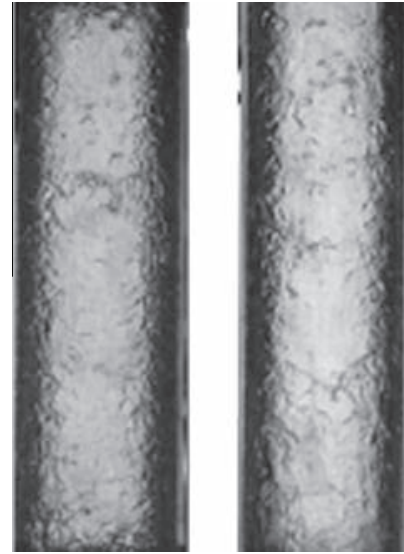

Fig. 8. Flow visualisation for annular flow $G=200 \mathrm{~kg} / \mathrm{m}^{2} / \mathrm{s}$ and $x=0.20$ : left in $1-g$, right in $\mu-g$.
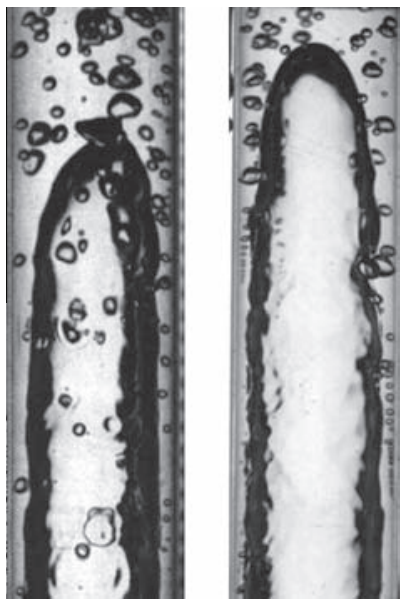

Fig. 9. Flow visualisation for slug flow at $G=220 \mathrm{~kg} / \mathrm{m}^{2} / \mathrm{s}$ and $x=0.05$ : left in $1-g$, right in $\mu-g$.

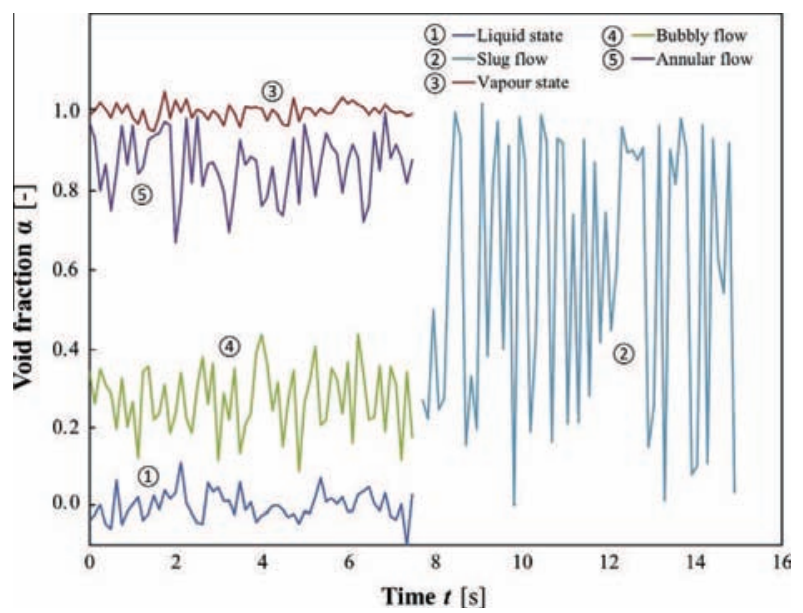

Fig. 10. Void fraction time evolution in single-phase liquid and vapour flows and in two-phase bubbly, slug and annular flows.

performed on an adiabatic part of the test section. In microgravity, the last term of the RHS is negligible and the measured pressure drop is directly proportional to the wall shear stress. In normal gravity (vertical upward flow), the hydrostatic pressure drop has to be deduced from total measurement. A good estimation of the

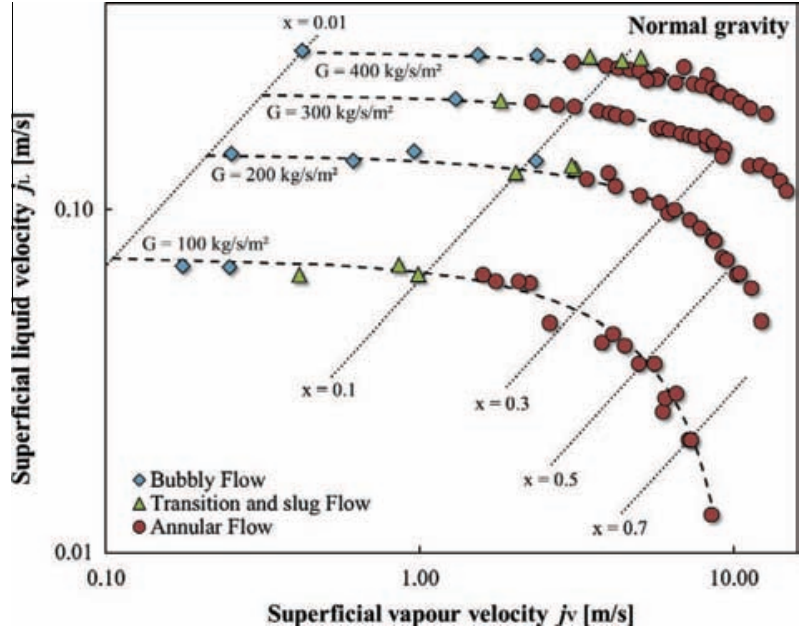

Fig. 11. Flow pattern map for normal gravity experiments.

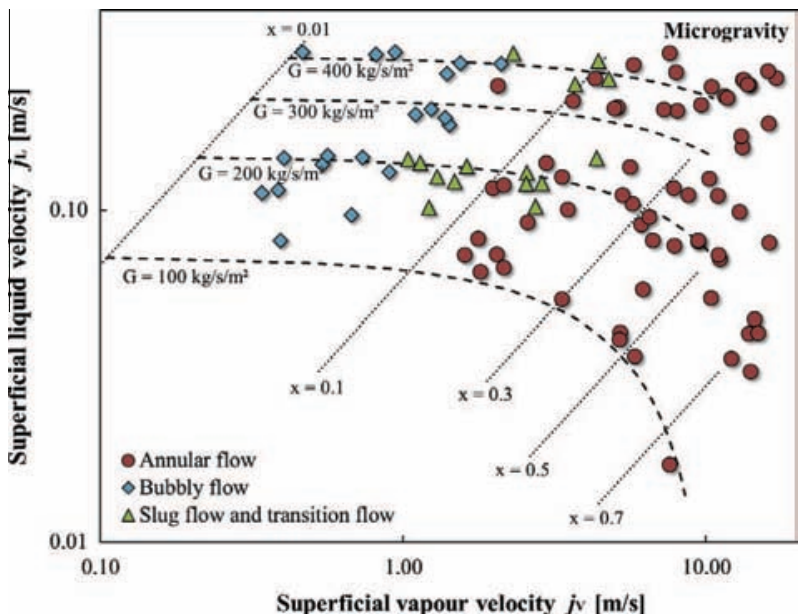

Fig. 12. Flow pattern map for microgravity experiments.

wall shear stress in this configuration requires an accurate measurement of the void fraction.

The experimental data are compared to the prediction of Lockhart and Martinelli's correlation (Lockhart and Martinelli, 1949), that gives an expression of the two-phase multiplier $\phi_{L}$ versus the Martinelli parameter $X$ :

$$
\begin{aligned}
\left(\frac{d P}{d z}\right)_{f r} & =\phi_{L}^{2} \cdot\left(\frac{d P}{d z}\right)_{l} \text { with } \phi_{L}^{2}=1+\frac{C}{X}+\frac{1}{X^{2}} \text { and } \\
X^{2} & =\left(\frac{d P}{d z}\right)_{l} /\left(\frac{d P}{d z}\right)_{v}
\end{aligned}
$$

where $\left(\frac{d P}{d z}\right)_{l}$ and $\left(\frac{d P}{d z}\right)_{v}$ would be the frictional pressure drops if the liquid or vapour were flowing alone in the tube. The constant $C$ is equal to 20 if liquid and vapour Reynolds numbers are above 2000 (turbulent flow referred as $L M_{t t}$ in Fig. 13) and $C$ is equal to 10 if liquid Reynolds number is below 2000 (laminar regime) and vapour Reynolds number above 2000 (referred as $L M_{l t}$ ). Fig. 13 represents the experimental two-phase multiplier $\phi_{L}$ under normal gravity and microgravity conditions, compared to the one predicted by Lockhart and Martinelli's correlation.

A good agreement is obtained especially in annular flow regimes. The discrepancy between experiments and the model for bubbly flow in normal gravity may be attributed to a significant error on the superficial vapour velocity for low vapour qualities 


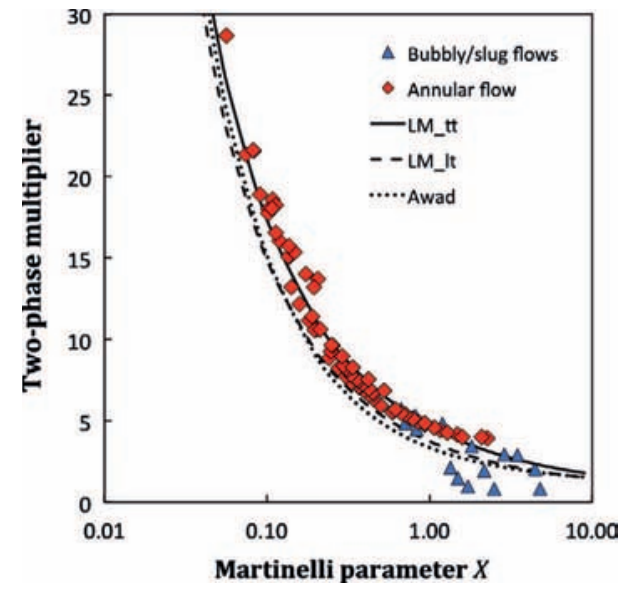

(a) Normal gravity

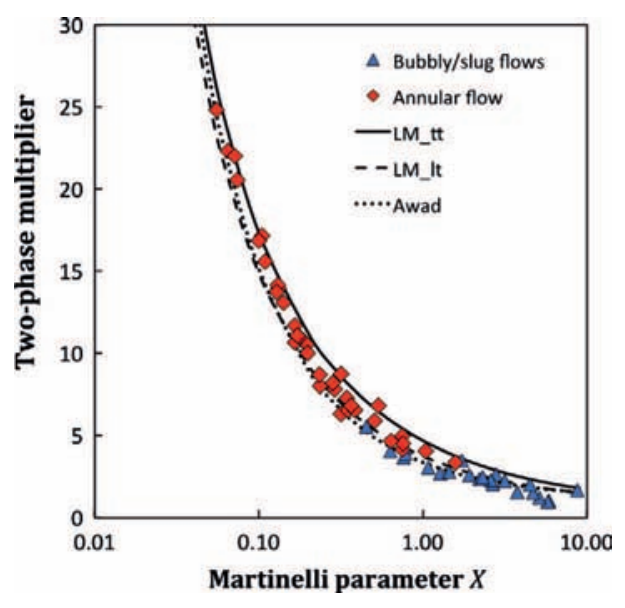

(b) Microgravity conditions.

Fig. 13. Frictional pressure drop: two-phase multiplier.

and also to larger measurement errors on the pressure drop for bubbly flows. For microgravity experiments, an improvement of the two-phase multiplier model has been proposed by (Awad and Muzychka, 2010) and is also in very good agreement with experimental data:

$\phi_{L}^{2}=\left[1+\left(\frac{1}{X^{2}}\right)^{2 / 7}\right]^{7 / 2}$

From the measurement of the pressure drop and the void fraction or the film thickness, it is possible to determine the interfacial shear stress $\tau_{i}$ from the momentum balance equation for the vapour core (Wallis, 1969):

$-\alpha \frac{d P}{d z}-\frac{4 \tau_{i} \sqrt{\alpha}}{D}-\rho_{v} \alpha g=0$

Eq. (12) is written for an annular flow without liquid droplet entrainment, assumption that will be justified in the next section. The interfacial friction factor $f_{i}$ can be calculated according to $\tau_{i}$ :

$f_{i}=\frac{\tau_{i}}{0.5 \rho_{v}\left(U_{v}-U_{l}\right)^{2}} \simeq \frac{\tau_{i}}{0.5 \rho_{v} U_{v}^{2}}$

and compared to the wall friction factor of a vapour flow on the smooth wall $f_{v}$ :

$f_{v}=0.079 R e_{v}^{-1 / 4}$ with $R e_{v}=\frac{U_{v} D}{v_{v}}$

In annular flow, the vapour velocity $U_{v}$ is most of the time much higher than the liquid velocity $U_{l}$. This high velocity difference leads to a destabilisation of the interface of the liquid film, which becomes wavy. For annular wavy liquid films, Wallis (1969) proposed an expression of the interfacial friction factor linked to the roughness of the liquid film that is assumed to equal the film thickness:

$\frac{f_{i}}{f_{v}}=1+300 \frac{\delta}{D}$

This correlation was developed for two-phase flow in large tubes (diameters around $50 \mathrm{~mm}$ ). In this configuration, $f_{v}$ is equal to about 0.005 and almost independent of $R_{v}$ corresponding to a fully-rough turbulent flow. Very few measurements of the interfacial shear stress have been performed in millimetric diameter tubes and almost no measurements exist in microgravity conditions. A data set is reported in $12.7 \mathrm{~mm}$ diameter tube in microgravity by Bousman and Dukler (1993), who provided a correlation for the prediction of $f_{i} / f_{v}$ : $\frac{f_{i}}{f_{v}}=211.4-245.9 \alpha$

The interfacial friction factor is calculated from our experiments. $f_{i} / f_{v}$ is plotted versus the dimensionless film thickness $\delta / D$ characterising the film roughness in Fig. 14a and compared to the correlations of Wallis (1969) and Bousman and Dukler (1993). The Wallis's correlation largely overpredicts the interfacial friction factor and the Bousman and Dukler's correlation seems to be in reasonable agreement with the $1-g$ data. In Fig. 14b, the values of $f_{i} / f_{v}$ are plotted versus the vapour Reynolds number $R e_{v}$ based on the vapour velocity and on the diameter of the vapour core $D \sqrt{\alpha} . f_{i} / f_{v}$ is a decreasing power function of $\operatorname{Re}_{v}: f_{i} / f_{v} \sim R e_{v}^{-1.3}$. The dependency of $f_{i} / f_{v}$ with $\operatorname{Re}_{v}$ proves that the turbulent regime of the vapour core is not fully rough. For a given value of $R e_{v}$, the dimensionless interfacial friction factor $f_{i} / f_{v}$ seems to be lower in $\mu-g$ than in $1-g$, difference that increases while the mass flux decreases. Nevertheless it is important to remark that the friction factor also depends on the film thickness that is different in $\mu-g$ and in $1-g$.

As suggested by Lopez and Dukler (1986), the dependency on both roughness and Reynolds number is characteristic of a transition between smooth and fully rough turbulent regimes. For this partly rough turbulent regime, Fore et al. (2000) proposed a correction to the Wallis's correlation introducing a function of the vapour Reynolds number as $1+A / R e_{v}$. Following this approach, a relation between $f_{i} / f_{v}, \operatorname{Re}_{v}$ and $\delta / D$ is proposed. $f_{i} / f_{v}$ is plotted versus $\left(1+3.10^{5} / \operatorname{Re}_{v}^{1.3}\right)(\delta / D)^{0.1}$ in Fig. 15. The power of the vapour Reynolds number is equal to -1.3 as shown in Fig. 14. The power of $(\delta / D)$ is much smaller than in the Wallis correlation. The following equation provides a reasonable prediction of the interfacial friction factor for the highest mass fluxes (Fig. 15). However large discrepancies are found the lowest mass flux $G=100 \mathrm{~kg} / \mathrm{m}^{2} / \mathrm{s}$, especially in microgravity. Specific experiments at low mass fluxes will be performed in the future.

$\frac{f_{i}}{f_{v}}=1+28\left[\left(1+\frac{3 \cdot 10^{5}}{\operatorname{Re}_{v}^{1.3}}\right)\left(\frac{\delta}{D}\right)^{0.1}-0.82\right]$

\subsection{Void fraction and film thickness}

For bubbly and slug flows, it is possible to calculate the value of the mean vapour velocity from the void fraction measurements. In Fig. 16, the mean vapour velocity $U_{v}$ is plotted versus the mixture velocity $j$ and compared to the classical drift flux model of Zuber and Findlay (1965): 


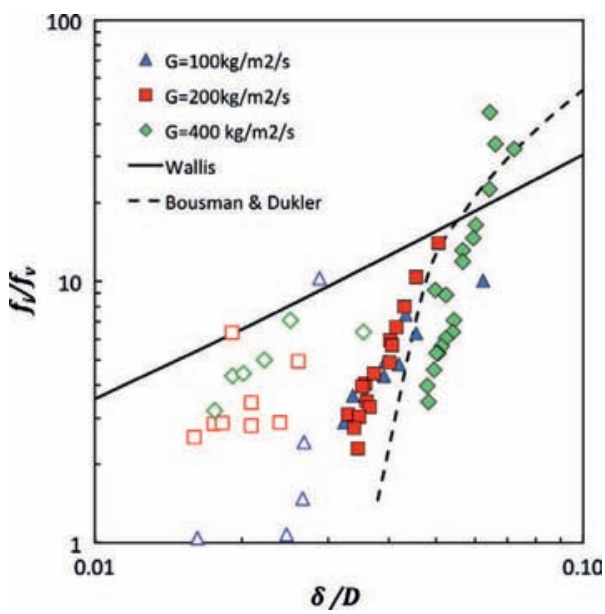

(a) $f_{i} / f_{v}$ versus film thickness

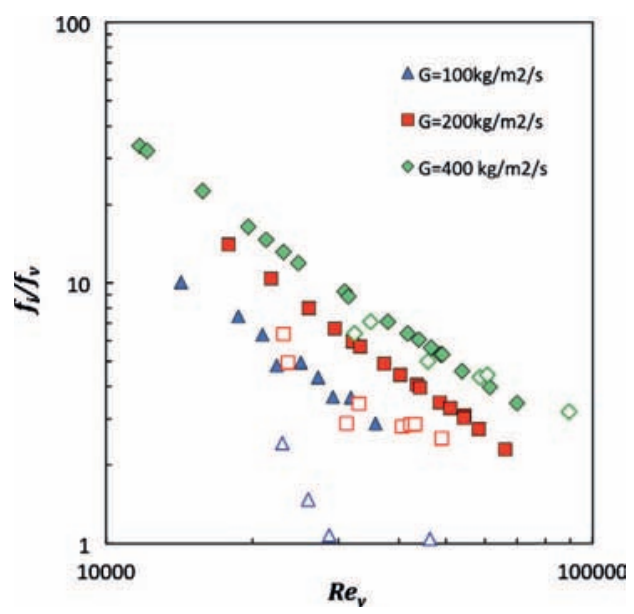

(b) $f_{i} / f_{v}$ versus vapor Reynolds number.

Fig. 14. Interfacial friction factor in $1-g$ (closed symbol) and in $\mu-g$ (open symbols) experiments.

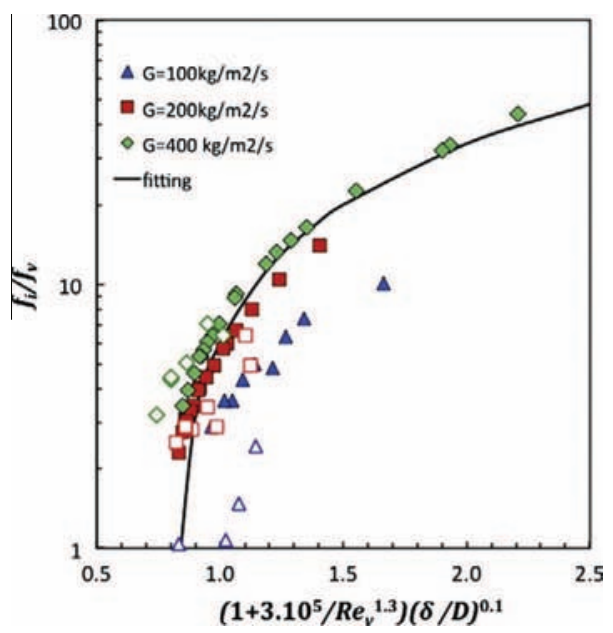

Fig. 15. prediction of interfacial friction factor in $1-g$ (closed symbols) and $\mu-g$ conditions (open symbols), solid line Eq. (17).

$U_{v}=\frac{j_{v}}{\alpha}=C_{0} \cdot j+U_{\infty}=C_{0} \cdot\left(j_{l}+j_{v}\right)+U_{\infty}$

where the drift velocity $U_{\infty}$ has different expressions for bubbly and slug flows: $U_{\infty}=1.53\left(g\left(\rho_{l}-\rho_{v}\right) \sigma / \rho_{l}^{2}\right)^{1 / 4}$ (Harmathy, 1960) for bubbly flows and $U_{\infty}=0.35 \sqrt{g D}$ (Niklin et al., 1962) for Taylor bubbles in slug flow. These values are around $0.1 \mathrm{~m} / \mathrm{s}$ in our experiments. In microgravity, $U_{\infty}$ is equal to zero and a good agreement with Eq. (18) is found for a value of $C_{0}$ equal to 1.3.

This confirms the results previously obtained by Colin et al. (1991, 1996) for air-water flows in tubes of different diameters. The data on ground are compared to Eq. (18) for the same value of $C_{0}$ and a drift velocity for a bubbly flow $U_{\infty}=0.15 \mathrm{~m} / \mathrm{s}$. The scattering of the experimental data around the predicted values may be explained by the lower accuracy on the measurements for the very low quality values.

In the annular flow regime, the liquid film thickness $\delta$ can be deduced from the void fraction measurement by geometrical considerations. If there is no liquid droplet entrainment in the gas core, all the liquid flows at the wall and $\delta=D / 2(1-\sqrt{\alpha})$. The accuracy on the film thickness measurement is linked to the capacitance measurement accuracy and the calibration procedure. For an accuracy of $2 \%$ on the void fraction value, the relative error on the film thickness is about $7 \%$. A film thickness of $300 \mu \mathrm{m}$ is evaluated with

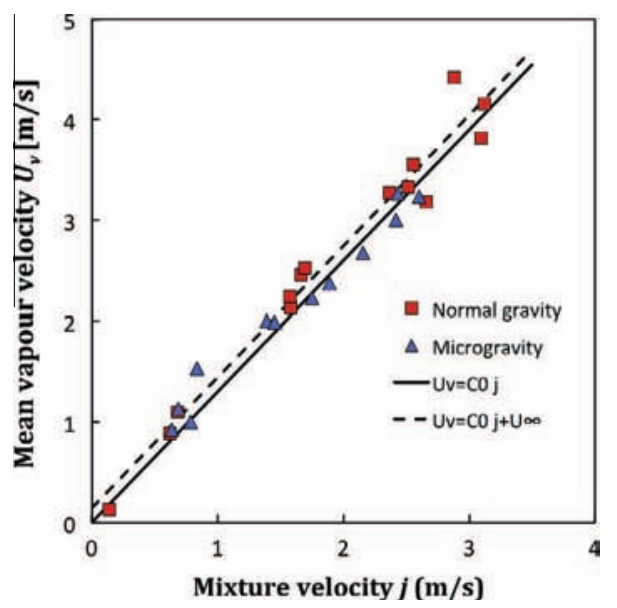

Fig. 16. Mean gas velocity for bubbly and slug flows in subcooled boiling. Comparison with the drift flux model for $C_{0}=1.3$.

an accuracy of $20 \mu \mathrm{m}$. If there is an entrainment rate $e$, it has to be taken into account in the calculation of the film thickness (Cioncolini et al., 2009):

$\delta=\frac{D}{2}\left(1-\sqrt{\alpha \frac{\rho_{l} x+\rho_{v}(1-x) e}{\rho_{l} x}}\right)$

Since the void fraction sensor provides a void fraction measurement almost independent of the phase distribution, only a global measurement of the liquid holdup, including both liquid film and droplets is obtained. In order to evaluate the rate of entrainment in our experiments and its influence on the film thickness measurement, it has been evaluated by using the correlation of Cioncolini and Thome (2012):

$e=\left(1+279.6 W e_{c}^{-0.8395}\right)^{-2.209}$

where $W e_{c}$ is the Weber number of the vapour core based on the superficial vapour velocity and on the density $\rho_{c}$ of the vapour core carrying droplets:

$W e_{c}=\frac{\rho_{c} j_{v}^{2} D}{\sigma} \quad$ with $\quad \rho_{c}=\frac{x+e(1-x)}{\frac{x}{\rho_{g}}+\frac{e(1-x)}{\rho_{l}}}$ 
The Weber number $W e_{c}$ ranges between 10 and $10^{5}$. From Eq. (19), it is possible to estimate the absolute error made by neglecting entrainment on the film thickness evaluation. This error is about equal to $\left(\rho_{g}(1-x) e\right) /\left(2 \rho_{l} x\right)$. For the range of our experimental parameters $G$ between 100 and $400 \mathrm{~kg} / \mathrm{m}^{2} / \mathrm{s}$ and $x$ up to $0.8, e$ has been estimated from Eq. (20). The highest value found for the absolute error is 5\%. Nevertheless, entrainment has been taken into account in the calculations for a better estimation of the film thickness.

In Fig. 17, the film thickness is plotted versus quality for three mass fluxes $G$ in normal gravity and microgravity conditions. The accuracy on the film thickness measurement is about $20 \mu \mathrm{m}$. It can clearly be seen that for qualities larger than 0.2 , the film thickness is larger in normal gravity than in microgravity. It can be explained from the momentum balance equations for the liquid film and the gas core. By eliminating the pressure gradient between these two equations and neglecting the acceleration term, a relation between the void fraction, the wall shear stress $\tau_{w}$ and the interfacial shear stress $\tau_{i}$ is obtained:

$-\tau_{w} \cdot \sqrt{\alpha}+\tau_{i}-\left(\rho_{l}-\rho_{g}\right) g \cdot \sqrt{\alpha}(1-\alpha) D / 4=0$

$\tau_{w}, \tau_{i}$ and $g$ the gravity acceleration are positive in this equation. Then the first term is negative, the second one positive and the third one negative. In microgravity, this equation reduces to $\tau_{w} \cdot \sqrt{\alpha}=\tau_{i}$. In vertical upward flow in normal gravity, the interfacial shear stress has to compensate both gravity and wall shear stress. Even if the interfacial shear stress is a little bit larger in normal gravity than in microgravity, this larger value cannot compensate the gravity term. The first term of Eq. (22) has to be lower in normal gravity. Since the wall shear stress is about the same in $1-g$ and $\mu-g$, it means that the void fraction has to be lower and the film thickness larger, which is in agreement with the experimental results. In Fig. 17, the measured film thickness values are also compared to the theoretical film thickness values calculated by Cioncolini and Thome (2011) using an algebraic eddy viscosity model for describing the velocity profile in the turbulent liquid film of an annular flow:

$\delta=y_{\star} \cdot \max \left[\sqrt{\frac{2 \Gamma_{l f}^{+}}{R^{+}}} ; 0.0066 \frac{\Gamma_{l f}^{+}}{R^{+}}\right]$

where $y_{\star}=v_{l} / u_{\star}$ is the viscous length scale, $R^{+}=D / 2 y_{\star}$ is the dimensionless pipe radius and $\Gamma_{l f}^{+}$the dimensionless mass flow rate in the liquid film:
$\Gamma_{l f}^{+}=\frac{(1-e)(1-x) G \pi \cdot D^{2}}{8 \pi \rho_{l} u_{\star} y_{\star}^{2}}$

In Eqs. (23) and (24), the friction velocity $u_{\star}=\sqrt{\tau_{w} / \rho_{l}}$ is evaluated according to Cioncolini et al. (2009):

$\tau_{w}=\frac{1}{2} f_{w l} \rho_{c} V_{c}^{2}$ with $f_{w l}=0.172 W e_{c}^{2}$

where the Weber number $W e_{c}$ is based on the core density $\rho_{c}$, core mean velocity $V_{c}$ and core diameter $d_{c}$. In these calculations, the following expression has been used for the estimation of the void fraction in annular flow:

$$
\begin{aligned}
\alpha & =\frac{f \cdot x^{n}}{1+(f-1) \cdot x^{n}} \text { with } f=a+(1-a)\left(\frac{\rho_{v}}{\rho_{l}}\right)^{a_{1}} \text { and } n \\
& =b+(1-b)\left(\frac{\rho_{v}}{\rho_{l}}\right)^{b_{1}}
\end{aligned}
$$

with $a=-2.129, b=0.3487, a_{1}=-0.2186, b_{1}=0.515$. The measurements of the void fraction in microgravity are in reasonable agreement with the prediction of Eq. (26), whereas this equation largely overpredicts the measurement in $1-g$ conditions. Then, the measurements of the liquid film thickness are in good agreement with the prediction of Eq. (23) in microgravity. In normal gravity, the model largely underpredicts the measured values, because of the overestimation of the void fraction, as can be seen in Fig. 18.

\subsection{Heat Transfer Coefficient}

The heat transfer coefficients in saturated and subcooled boiling in $1-g$ and $\mu-g$ are deduced from the wall heat flux measurements $q$ and the wall (given by the second probe near the imaged part of the tube) and liquid bulk temperatures using Eq. (4). By using a linear evolution of the temperature in the heated section and by considering uncertainties $\Delta q$ and $\Delta T$ on the heat flux and temperature difference, respectively, heat transfer coefficients can be calculated with an error of $\pm 14 \%$. In saturated boiling corresponding to annular flow, the heat transfer coefficients are plotted in Fig. 19a and compared to the classical correlations of Kandlikar (1990) and Chen (1966). For vertical flows, Kandlikar' s correlation gives the value of the heat transfer coefficient:

$h=h_{l}\left[C_{1} C^{C_{2}}+C_{3} B^{C_{4}} F_{K}\right]$

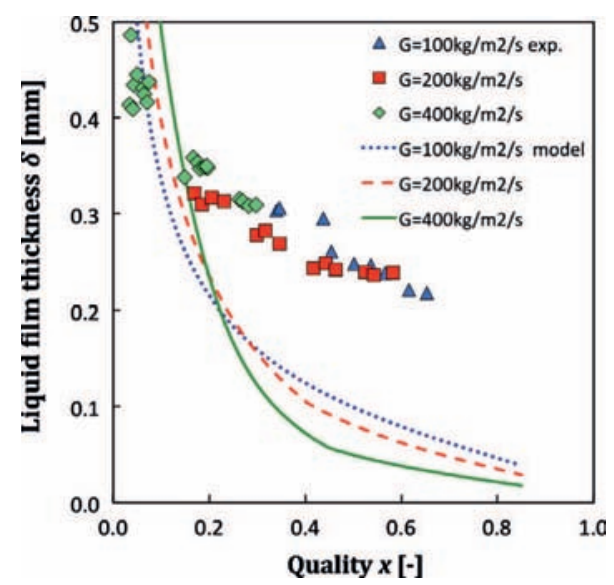

(a) Normal gravity

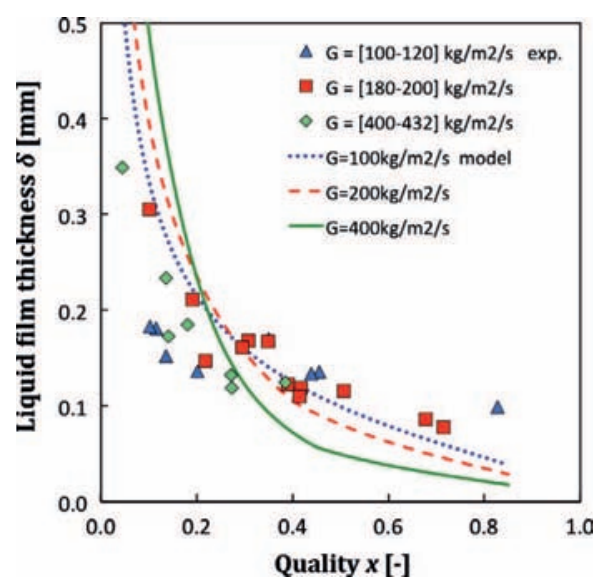

(b) Microgravity conditions.

Fig. 17. Liquid film thickness in annular flow - symbols: experiments - lines: Eq. (23). 


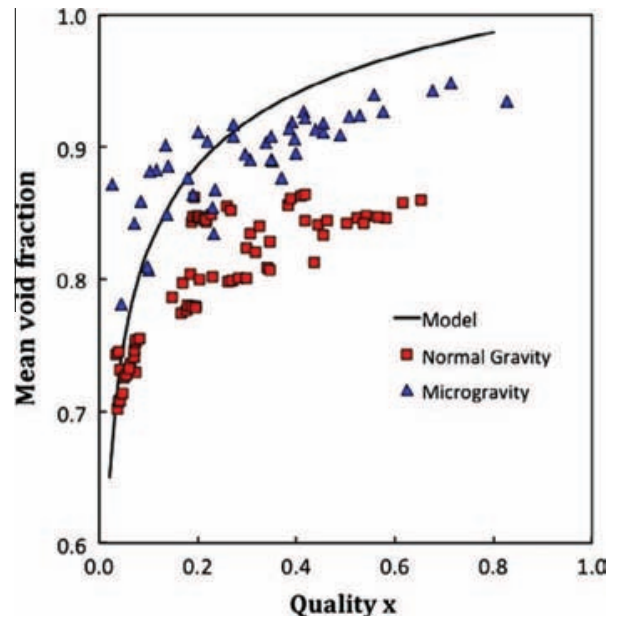

Fig. 18. Void fraction versus quality in $1-g$ (squares) and $\mu-g$ conditions (triangles), solid line Eq. (26).

where $h_{l}$ is the heat transfer coefficient for a liquid single-phase flow at velocity $j_{l}, B o=\frac{q}{G h_{l v}}$ is the Boiling number and Co $=\left(\frac{1-x}{x}\right)^{0.8} \sqrt{\frac{\rho_{g}}{\rho_{l}}}$ a convection number. The values of the constants are for $C_{0}<0.65, C_{1}=1.136, C_{2}=-0.9, C_{3}=667.2, C_{4}=0.7$ and for $C_{0}>0.65, C_{1}=0.6683, C_{2}=-0.2, C_{3}=1058, C_{4}=0.7$. The value of $F_{K}$ has been taken equal to 1.3 , close to those of similar refrigerants.

The heat transfer coefficient can also be calculated using Chen's correlation:

$h=F \cdot h_{l}+S \cdot h_{n b}$

where $h_{n b}$ is the heat transfer coefficient in pool boiling:

$$
\begin{aligned}
h_{n b}= & 0.00122\left[\frac{k_{l}^{0.79} C p_{l}^{0.45} \rho_{l}^{0.49}}{\sigma^{0.5} \mu_{l}^{0.29} h_{l v} 0.24 \rho_{v}^{0.24}}\right] \cdot\left(T_{w}-T_{\text {sat }}\right)^{0.24} \\
& \cdot\left(P_{\text {sat }}\left(T_{w}\right)-P_{\text {sat }}\right)^{0.75}
\end{aligned}
$$

and $F$ and $S$ are amplification and suppression factors, function of Martinelli's parameter $X$ :

$F(X)=2.35\left(0.213+\frac{1}{X}\right)^{0.736}$ if $\frac{1}{X}>0.1$ else $F(X)=1$

$$
S(X)=\frac{1}{1+2.53 \cdot 10^{-6} \cdot\left(\frac{G D(1-x) F(x)^{1.25}}{\mu_{l}}\right)^{1.17}}
$$

Experimental data correspond with wall heat fluxes $q=1,2$, $4 \mathrm{~W} / \mathrm{cm}^{2}$. Indeed, the wall heat flux has a rather small influence on the heat transfer coefficient and was therefore not distinctly plotted, for clarity reasons. Chen's and Kandlikar's correlations are given for $q=2 \mathrm{~W} / \mathrm{cm}^{2}$.

Chen's correlation seems to underpredict the experimental data, especially at high quality, whereas Kandlikar's correlation gives a better prediction of the data. Nevertheless, it overpredicts the data for lower mass fluxes and lower qualities.

The experimental data are also compared to the heat transfer coefficient (HTC) estimated by Cioncolini and Thome (2011), according to the film thickness and wall friction in Fig. 19b:

$h=\frac{k_{l}}{\delta} 0.0776 \cdot \delta^{+0.9} \operatorname{Pr}_{l}^{0.52} \quad \delta^{+}=\frac{\delta}{y_{\star}}$

This expression is valid for $10<\delta^{+}<800$ and $0.86<P r_{l}<6.1$. This model seems able to reproduce the experimental trend, except for the highest high flux $G=400 \mathrm{~kg} / \mathrm{m}^{2} / \mathrm{s}$ and the lowest qualities $x<0.2$. In order to better check the accuracy of the model, the predicted value of heat transfer coefficients by Eq. (32) is plotted versus the measured ones in Fig. 20. In Fig. 20a, the values of $\delta$ and $u_{\star}$ are calculated using Eqs. (23) and (25), whereas in Fig. 20b, the experimental values of $\delta$ and $u_{\star}$ are used for the calculations.

In Fig. 20a, the agreement is better than $\pm 20 \%$ for most of the data, except for $1-g$ data at high heat flux. Despite the large discrepancy of the model and the data on the film thickness in $1-g$ (see Fig. 17), a reasonable agreement in found on the heat transfer coefficient. It may be explained by the small dependency of the heat transfer coefficient to the film thickness in Eq. (32): $h \propto \delta^{0.1}$. A significant difference is also found between the measured values of the wall shear stress $\tau_{w}$ and the prediction of Eq. (25). Then experimental data have finally be compared to the prediction of Eq. (32) using the experimental values for $\delta$ and $u_{\star}$. A much better agreement is found in this case, with most of the data predicted in a range of accuracy of $\pm 15 \%$, except for a few data at the lowest mass flux in microgravity.

An explanation for the low sensitivity of the heat transfer coefficient to gravity can be found by looking at the temperature and velocity profiles provided by Cioncolini for thick turbulent liquid films: both temperature and velocity gradients are concentrated

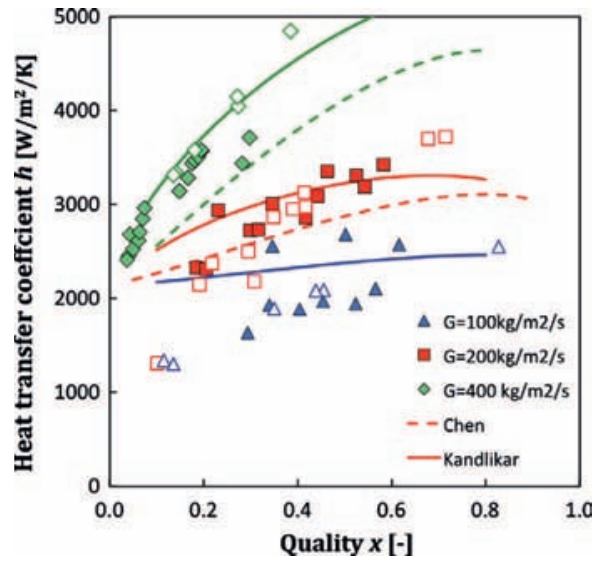

(a) Comparison with Chen and Kandlikar correlations

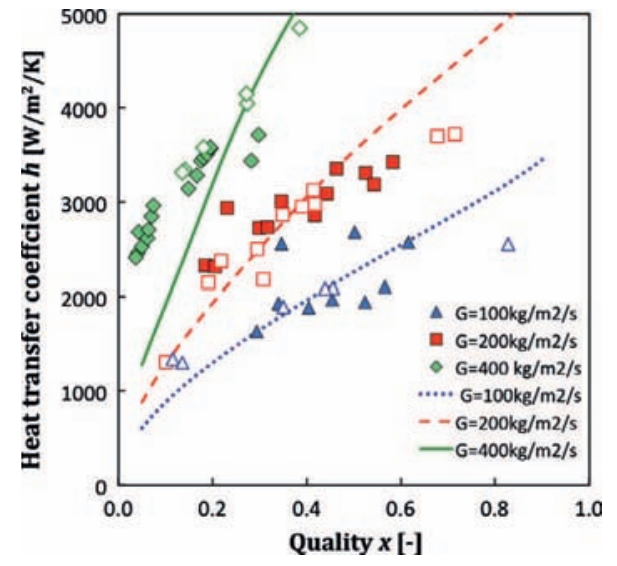

(b) Comparison with Cioncolini and Thome's model.

Fig. 19. Heat Transfer Coefficients versus quality for different mass fluxes in $1-g$ (closed symbols) and in $\mu-g$ (open symbols). 


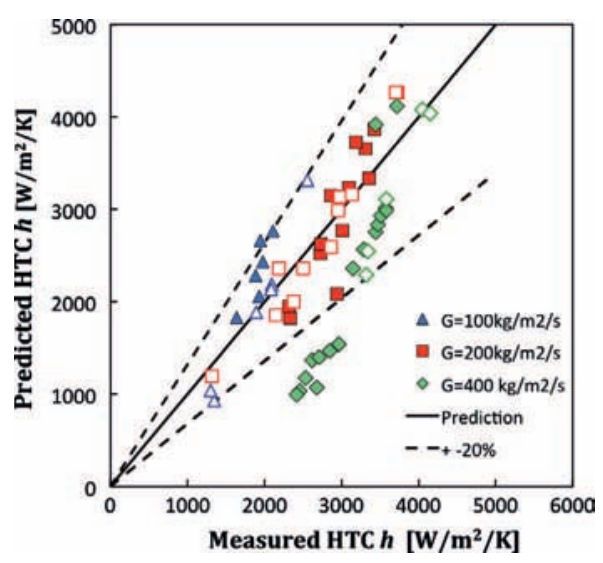

(a) HTC calculated by eq.(32) using eq. (23) and (25)

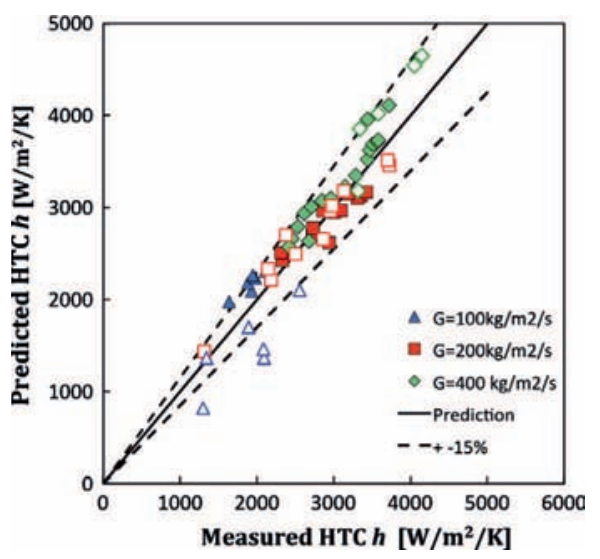

(b) HTC calculated by eq.(32) and experimental values of $\delta$ and $u_{\star}$

Fig. 20. Comparison of the Cioncolini and Thome' s model with measured values for different mass fluxes in $1-g$ (closed symbols) and in $\mu-g$ (open symbols).

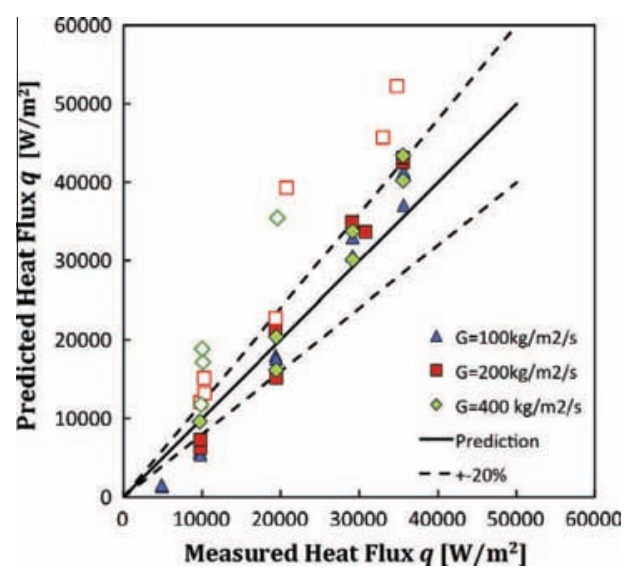

Fig. 21. Heat flux in subcooled boiling in $1-g$ (closed symbols) and in $\mu-g$ (open symbols).

near the wall on a range of dimensionless distance from the wall $0<y^{+}<30$. Yet experimental dimensionless liquid film thicknesses in $1-g$ for $G>100 \mathrm{~kg} / \mathrm{s} / \mathrm{m}^{2}$ correspond to $\delta^{+}>55$. Therefore, it can be assumed that a change in the film thickness due to various gravity levels will not consequently affect the velocity and temperature profiles near the wall, as long as the liquid film is thick enough $\left(\delta^{+}>30\right)$. That can explained the low sensitivity $\delta^{0.1}$ in the heat transfer coefficient modelling and in the measurements for $G>100 \mathrm{~kg} / \mathrm{s} / \mathrm{m}^{2}$.

For subcooled boiling, the flow regimes are mostly bubbly flows and also some slug flows. There are much fewer correlations that can predict HTC in subcooled boiling than in saturated boiling. Our data are compared to Chen's correlation whose application can also be extended to flow boiling with a low level of subcooling $\left(<20^{\circ} \mathrm{C}\right)$. The total heat flux is divided into one part due to convection of the subcooled liquid at temperature $T_{l}$ and another part due to the bubble nucleation on the wall:

$q=F(X) h_{l}\left(T_{w}-T_{l}\right)+h_{n b} S\left(T_{w}-T_{\text {sat }}\right)$

The heat fluxes predicted by Eq. (33) are plotted versus the experimental values in Fig. 21.

For on-ground experiments, a reasonable agreement is obtained between Chen's correlation and the experimental data. In microgravity condition, the wall heat flux is significantly lower (20\%) than in $1-g$ conditions, and much lower than expected from
Chen's correlation. The reason for this discrepancy is not very clear. It seems that in microgravity, for moderate and low mass fluxes, larger bubbles are formed on the wall before they detach (see Fig. 7c and d). The frequency of detachment of the bubbles is a little bit lower in microgravity, which could explained the reduced contribution of the heat flux due to nucleate boiling.

\section{Conclusion}

This paper presents the results of flow boiling experiments performed under microgravity conditions during two parabolic flight campaigns and compared to parametric runs conducted on ground. The objective was to collect heat transfer, void fraction and wall friction data in flow boiling in a $6 \mathrm{~mm}$ inner diameter heated sapphire tube, using HFE-7000 as working fluid. Special attention was paid to the calculation of the vapour quality in order to characterise properly the subcooled boiling regimes, but it remains difficult to investigate flows with very low superficial vapour velocities. Annular flow, slug flow and bubbly flow have been observed in videos according to the vapour quality and the mass fluxes. The results show that the gravity level has little impact on the flow for mass fluxes superior to $400 \mathrm{~kg} / \mathrm{m}^{2} / \mathrm{s}$ whatever the flow pattern is. That is the reason why lower mass fluxes were investigated in this article. The transition between slug and annular flows seems to occur at lower qualities in microgravity.

Experimental frictional pressure drops data fit Lockhart and Martinelli's correlation (Eq. (10)) with a good agreement both in normal gravity and microgravity (the wall shear stress being similar for these two gravity levels), although Awad's correlation gives a better prediction in microgravity. The interfacial shear stress has also been measured. The interfacial friction factor is characteristic of transition regime between a smooth and a fully-rough turbulent flow since it depends both on the film thickness (roughness) and the Reynolds number of the vapour core. Wallis's correlation is not adapted to predict the interfacial shear stress in this situation. A correlation depending on both vapour Reynolds number and film thickness has been proposed (Eq. (17)).

In annular flow, the film thickness is much lower in microgravity than in normal gravity, which can be explained by the momentum balance equation of the liquid film.

The heat transfer coefficient in saturated boiling and annular flow regimes seems to be weakly affected by gravity for $G$ values between 100 and $400 \mathrm{~kg} / \mathrm{m}^{2} / \mathrm{s}$. For $G$ equal to 200 and $400 \mathrm{~kg} / \mathrm{m}^{2} / \mathrm{s}$, the correlation of Kandlikar gives a good prediction 
of the heat transfer coefficient. The experimental data are also compared to the model of Cioncolini et Thome (Eq. (32)) that was developed for annular flow boiling. By using the experimental values for the wall shear stress and the film thickness, a very good agreement between the experimental data and the model was found. Despite the difference in the film thickness in $1-g$ and in $\mu-g$, the heat transfer coefficient is similar in $1-g$ and in $\mu-g$. This can be explained by the low dependency of the model to the film thickness. The heat transfer coefficient is mostly dependent of the wall shear stress, which is similar in $1-g$ and in $\mu-g$.

In subcooled boiling, the wall heat flux is compared to Chen's correlation (Eq. (33)). The influence of gravity is clearly visible on the results at low heat flux in microgravity, with heat transfer coefficient $20 \%$ lower in microgravity. The reason may be the lower bubble formation frequency under microgravity conditions.

In the future, new experiments at lower mass fluxes will be performed both on ground and in microgravity in order to highlight the gravity effect on larger ranges of parameters.

\section{Acknowledgements}

The authors would like to acknowledge the French and European Space Agencies CNES and ESA for having funded this study and the parabolic flight campaigns. The Fondation de Recherche pour l'Aéronautique et l'Espace is also thanked for its financial support.

\section{References}

Al-Arabi, M., 1982. Turbulent heat transfer in the entrance region of a tube. Heat Transfer Eng. 3, 76-83.

Awad, M.M., Muzychka, Y.S., 2010. Review and modeling of two-phase frictional pressure gradient at microgravity conditions. Fluid Engineering Division Summer Meeting ASME, Montreal.

Bousman, W.S., Dukler, A.E., 1993. Study of gas-liquid flow in microgravity: void fraction, pressure drop and flow pattern. Proceedings of the 1993 ASME Winter Meeting, New Orleans, LA, pp. 174-175.

Bousman, W.S., McQuillen, J.B., Witte, L.C., 1996. Gas-liquid flow patterns in microgravity: Effects of tube diameter, liquid viscosity and surface tension. Int. J. Multiphase Flow 22, 1035-1053.

Celata, G.P., Zummo, G., 2009. Flow boiling heat transfer in microgravity: recent progress. Multiphase Sci. Technol. 21, 187-212.

Chen, J.C., 1966. Correlation for boiling heat transfer to saturated fluids in convective flow. Ind. Eng. Chem. Proc. Des. Dev. 5, 322-339.

Chen, I.Y., Downing, R.S., Keshock, E., Al-Sharif, M., 1991. Measurements and correlation of two-phase pressure drop under microgravity conditions. J. Thermophys. 5, 514-523.

Cioncolini, A., Thome, J.R., Lombardi, C., 2009. Unified macro-to-microscale method to predict two-phase frictional pressure drops of annular flows. Int. J. Multiphase flows 35, 1138-1148.

Cioncolini, A., Thome, J.R., 2011. Algebraic turbulence modeling in adiabatic and evaporation annular two-phase flow. Int. J. Heat Fluid Flow 32, 805-817.

Cioncolini, A., Thome, J.R., 2012. Entrained liquid fraction prediction in adiabatic and evaporating annular two-phase flow. Nucl. Eng. Des. 243, 200-213.
Colin, C., Fabre, J., Dukler, A.E., 1991. Gas-liquid flow at microgravity conditions - I: Dispersed bubble and slug flow. Int. J. Multiphase Flow 17, 533-544.

Colin, C., Fabre, J., 1995. Gas-liquid pipe flow under microgravity conditions: influence of tube diameter on flow patterns and pressure drops. Adv. Space Res. $16,137-142$.

Colin, C., Fabre, J., McQuillen, J., 1996. Bubble and slug flow at microgravity conditions: state of knowledge and open questions. Chem. Eng. Com. 141-142, 155-173.

de Jong, P., Gabriel, K.S., 2003. A preliminary study of two-phase flow at microgravity: experimental data of film thickness. Int. J. Multiphase Flow 29, 1203-1220.

Dukler, A.E., Fabre, J.A., McQuillen, J.B., Vernon, R., 1988. Gas-liquid flow at microgravity conditions: flow pattern and their transitions. Int. J. Multiphase Flow 14, 389-400.

Elkow, K.J., Rezkallah, K.S., 1997. Void fraction measurements in gas-liquid flows under $1-g$ and $0-g$ conditions using capacitance sensors. Int. J. Multiphase Flow 23, 815-829.

Fang, X., Zhang, H., Xu, Y., Su, X., 2012. Evaluation of using two-phase frictional pressure drop correlations for normal gravity to microgravity and reduced gravity. Adv. Space Res. 49, 351-364.

Fore, L.B., Beus, S.G., Bauer, R.C., 2000. Interfacial friction in gas-liquid annular flow: analogies to full and transition roughness. Int. J. Multiphase Flow 26, 17551769.

Gnielinski, V., 1976. New equations for heat and mass transfer in turbulent pipe and channel flow. Int. Chem. Eng. 16, 359-368.

Harmathy, T., 1960. Velocity of large drops and bubbles in media of infinite and restrictive extent. AIChE J. 1, 289-295.

Jayawardena, S.S., Balakoaiah, V., Witte, L., 1997. Flow pattern transition maps in microgravity two-phase flows. AIChE J. 43, 1637-1640.

Kandlikar, S.G., 1990. A general correlation for saturated two-phase flow boiling heat transfer inside horizontal and vertical tubes. J. Heat Transfer 112, 219-228.

Kim, T.H., Kommer, E., Dessiatoun, S., Kim, J., 2012. Measurement of two-phase flow and heat transfer parameters using infrared thermometry. Int. J. Multiphase Flow 40, 56-67.

Lockhart, R.W., Martinelli, R.C. 1949. Proposed correlation of data for isothermal two-phase, two-component flow in pipes. Chem. Eng. Prog. Symp. Ser. 45, 3948.

Lopez, J.C.B., Dukler, A.E., 1986. Droplet entrainment in vertical annular flow and its contribution to momentum transfer. AIChE J. 32, 1500-1515.

Lui, R.K., Kawaji, M., Ogushi, T., 1994. An experimental investigation of subcooled flow boiling heat transfer under microgravity conditions. In: 10th International Heat Transfer Conference Brighton, 7, pp. 497-502.

Niklin, D.J., Wilkes, J.O., Davidson, J.F., 1962. Two-phase flow in vertical tubes. Trans. Instn. Chem. Eng. 40, 61-68.

Ohta, H., 1997. Experiments on microgravity boiling heat transfer by using transparent heaters. Nucl. Eng. Des. 175, 167-180.

Ohta, H., 2003. Microgravity heat transfer in flow boiling. Adv. Heat Transfer 37, 176.

Reinarts, T.R., 1993. Adiabatic two phase flow regime data and modeling for zero and reduced (horizontal flow) acceleration fields. PhD dissertation, Univ. of Texas A\&M.

Wallis, G.B., 1969. One Dimensional Two-Phase Flow. McGraw-Hill, New-York.

Zhao, L., Hu, W.R., 2000. Slug to annular flow transition of microgravity two-phase flow. Int. J. Multiphase Flow 26, 1295-1304.

Zhao, L., Rezkallah, K.S., 1993. Gas liquid flow patterns at microgravity conditions. Int. J. Multiphase Flow 19, 751-763.

Zhao, L., Rezkallah, K.S., 1995. Pressure drop in gas-liquid flow at microgravity conditions gas liquid flow patterns at microgravity conditions. Int. J. Multiphase Flow 21, 837-849.

Zuber, N., Findlay, J.A., 1965. Average volumetric concentration in two-phase systems. J. Heat Transfer, 453-468. 